\title{
Characterisation of the artificial neural network CiPS for cirrus cloud remote sensing with MSG/SEVIRI
}

\author{
Johan Strandgren, Jennifer Fricker, and Luca Bugliaro \\ Deutsches Zentrum für Luft- und Raumfahrt, Institut für Physik der Atmosphäre, Oberpfaffenhofen, Germany \\ Correspondence to: Johan Strandgren (johan.strandgren@dlr.de)
}

Received: 30 June 2017 - Discussion started: 3 July 2017

Revised: 18 September 2017 - Accepted: 19 September 2017 - Published: 14 November 2017

\begin{abstract}
Cirrus clouds remain one of the key uncertainties in atmospheric research. To better understand the properties and physical processes of cirrus clouds, accurate largescale observations from satellites are required. Artificial neural networks (ANNs) have proved to be a useful tool for cirrus cloud remote sensing. Since physics is not modelled explicitly in ANNs, a thorough characterisation of the networks is necessary.

In this paper the CiPS (Cirrus Properties from SEVIRI) algorithm is characterised using the space-borne lidar CALIOP. CiPS is composed of a set of ANNs for the cirrus cloud detection, opacity identification and the corresponding cloud top height, ice optical thickness and ice water path retrieval from the imager SEVIRI aboard the geostationary Meteosat Second Generation satellites. First, the retrieval accuracy is characterised with respect to different land surface types. The retrieval works best over water and vegetated surfaces, whereas a surface covered by permanent snow and ice or barren reduces the cirrus detection ability and increases the retrieval errors for the ice optical thickness and ice water path if the cirrus cloud is thin (optical thickness less than approx. 0.3). Second, the retrieval accuracy is characterised with respect to the vertical arrangement of liquid, ice clouds and aerosol layers as derived from CALIOP lidar data. The CiPS retrievals show little interference from liquid water clouds and aerosol layers below an observed cirrus cloud. A liquid water cloud vertically close or adjacent to the cirrus clearly increases the average retrieval errors for the optical thickness and ice water path, respectively, only for thin cirrus clouds with an optical thickness below 0.3 or ice water path below $5.0 \mathrm{~g} \mathrm{~m}^{-2}$. For the cloud top height retrieval, only aerosol layers affect the retrieval error, with an increased positive bias when the cirrus is at low altitudes. Third, the
\end{abstract}

CiPS retrieval error is characterised with respect to the properties of the investigated cirrus cloud (ice optical thickness and cloud top height). On average CiPS can retrieve the cirrus cloud top height with a relative error around $8 \%$ and no bias and the ice optical thickness with a relative error around $50 \%$ and bias around $\pm 10 \%$ for the most common combinations of cloud top height and ice optical thickness. Similarities with physically based retrieval methods are evident, which implies that even though the retrieval methods differ in the implementation of physics in the model, the retrievals behave similarly due to physical constraints. Finally, we also show that the ANN retrievals have a low sensitivity to radiometric noise in the SEVIRI observations. For optical thickness and ice water path the relative uncertainty due to noise is less than $10 \%$ down to sub-visual cirrus. For the cloud top height retrieval the uncertainty due to noise is around $100 \mathrm{~m}$ for all cloud top heights.

\section{Introduction}

Cirrus clouds remain one of the key uncertainties in atmospheric research (e.g. Waliser et al., 2009; Eliasson et al., 2011; Stevens and Bony, 2013). In particular, the net radiative forcing of cirrus clouds strongly depends on optical thickness, which mainly determines top-of-atmosphere (TOA) reflected shortwave radiation, and cloud height, which together with optical thickness defines the outgoing longwave flux (Meerkötter et al., 1999). To monitor and understand the properties of cirrus clouds, accurate and quantitative large-scale observations from satellites are required. Different satellite sensors used for cloud remote sensing have their individual strengths and weaknesses. Imaging radiome- 
ters like SEVIRI (Spinning Enhanced Visible InfraRed Imager; Schmetz et al., 2002), ABI (Advanced Baseline Imager; Schmit et al., 2015), MODIS (Moderate Resolution Imaging Spectroradiometer; King et al., 1992) and AVHRR (Advanced Very High Resolution Radiometer; Hastings and Emery, 1992) measure the longwave radiation emitted by the Earth and the reflected solar radiation leaving the Earthatmosphere system at TOA. Imaging radiometers typically view an area large enough (by scanning or otherwise) to observe complete cloud systems, but a passive infrared imager cannot resolve vertical cloud features and has a limited sensitivity to thin and sub-visual (visible optical thickness < 0.03) cirrus clouds. Active sensors like CALIOP (Cloud-Aerosol Lidar with Orthogonal Polarization; Winker et al., 2003, 2009) and CPR (Cloud Profiling Radar; Stephens et al., 2002) emit visible (CALIOP) and microwave radiation (CPR) and measure the radiation backscattered by clouds and aerosols. This allows for vertical profiling of clouds and aerosols along the satellite track with a high sensitivity to thin cirrus clouds (using the lidar). However, those sensors have a small footprint and observe only at nadir, which leads to a poor spatial coverage.

Observations from different satellite orbits generate additional advantages and limitations. Sensors observing the Earth from polar orbits (e.g. MODIS, AVHRR, CALIOP and CPR) have a near-global coverage and high spatial resolution but a low to poor temporal resolution, depending on the swath width/spatial coverage. In contrast, a geostationary imager like SEVIRI lacks a global coverage but has a constant large field of view, which allows for a high temporal resolution of $15 \mathrm{~min}$ (Schmetz et al., 2002) required to study the temporal evolution, life cycle and physical processes of clouds.

The advantages of individual instruments can be combined to enhance cloud retrievals if two or more complementary satellite sensors operate aboard the same satellite platform (e.g. the synergistic retrievals for the IIR thermal camera and CALIOP aboard CALIPSO (Cloud-Aerosol Lidar and Infrared Pathfinder Satellite Observations) by Garnier et al., $2012,2013,2015$ ) or fly in a satellite constellation like the Atrain (e.g. the synergistic retrievals for CALIOP and CPR or CALIOP, CPR and MODIS by Donovan and van Lammeren, 2001; Deng et al., 2010; Ceccaldi et al., 2013; Delanoë and Hogan, 2008, 2010).

Combining the advantages of satellite sensors operating in different orbits is more challenging, as they observe given scenes at different times from possibly different perspectives. Nevertheless, the information from available sensor collocations can be used to learn relationships between different sets of observations, e.g. through machine learning. For cloud remote sensing, artificial neural networks (ANNs) have proven to be a powerful tool for this (Kox et al., 2014; Holl et al., 2014; Minnis et al., 2016; Strandgren et al., 2017). Kox et al. (2014) developed an ANN-based algorithm trained with coincident SEVIRI thermal observations and CALIOP prod- ucts for the cloud top height (CTH) and ice optical thickness (IOT) determination of cirrus clouds from SEVIRI. Strandgren et al. (2017) exploit the main idea of Kox et al. (2014) and combine four ANNs trained with SEVIRI thermal observations, model data and CALIOP products for the detection of thin cirrus clouds and the retrieval of the corresponding CTH, IOT and ice water path (IWP) along with an additional opacity information. Holl et al. (2014) utilise ANNs trained with coincident CALIOP, CPR, AVHRR and MHS (Microwave Humidity Sounder) retrievals for the detection and IWP determination of ice clouds from AVHRR and MHS observations. Minnis et al. (2016) estimate the optical thickness of opaque ice clouds at night using an ANN trained with collocated MODIS IR observations and CPR retrievals. The ultimate goal with these approaches is to retrieve, respectively, CALIOP-, CALIOP/CPR- and CPR-like cloud properties from SEVIRI, AVHRR/MHS and MODIS observations alone. Although ANNs are a powerful alternative to physically based cloud retrievals (e.g. Platnick et al., 2003; Bugliaro et al., 2011; Minnis et al., 2011; Stengel et al., 2014; Heidinger et al., 2015; Wang et al., 2016; Iwabuchi et al., 2016), they are trained to learn patterns and model relationships, and physical principles are not imposed for the scenes being investigated. Consequently, it is difficult to predict how sensitive the retrievals are to different land surface types and the wealth of natural atmospheric situations and if there are physical conditions where the ANNs are incapable of retrieving meaningful results. This might be due to a number of reasons. On one hand, the channels of the imager possess a limited vertical resolution expressed by the channel weighting functions as a result of the wavelengthand temperature-dependent absorption, emission and scattering interactions with gas, cloud and aerosol layers in the atmosphere. On the other hand, ANNs will in general perform better for retrieval scenes that occur more frequently in the training dataset as those scenes will have a stronger weight during the training. This, together with the fact that ANNs provide no direct uncertainty estimates, highlights the importance of properly characterising the ANN retrievals.

In this paper we address those aspects by characterising the CiPS (Cirrus Properties from SEVIRI; Strandgren et al., 2017) algorithm in order to increase the understanding about the functionality, performance and robustness of the corresponding ANNs under different, sometimes challenging, retrieval conditions. SEVIRI and CALIOP, the main input and output training data sources used for CiPS, represent very different instruments. The active CALIOP lidar provides vertical profiles of ice cloud extinction and makes use of polarisation to distinguish between liquid water and ice. The CiPS algorithm finally exploits the brightness temperatures of the Earth sensed by the passive imager SEVIRI to detect ice clouds and derive their optical and physical properties. Although the physics underlying the two retrievals have similarities, like the fact that both instruments saturate at relatively low IOTs (between 3 and 5), the measurement types 
are very different. Thus, one shall evaluate in detail how effective the combination of these two instruments is in reality and whether there are situations where their different characteristics lead to unreliable results.

In Sect. 2 the satellite sensors and data used for the characterisation are briefly introduced. The CiPS algorithm is described in Sect. 3. The relative importance of the input variables used by CiPS is estimated in Sect. 4.2. This information is valuable for further ANN developments within the field of (cirrus) cloud remote sensing. In Sect. 4.3 the CiPS retrieval accuracy is characterised as a function of the underlying surface type, using a set of five surface type classes extracted from MODIS L3 data. In Sect. 4.4 we compare the retrieval accuracy of CiPS for scenes with clear air, aerosol layers and high and low liquid water clouds below the cirrus, using vertical characteristics of aerosol and cloud layers derived from CALIOP L2 data. Furthermore, we analyse the retrieval errors of CiPS as a function of IOT and CTH in Sect. 4.5, in order to quantify the retrieval error for different types of cirrus. This provides valuable information about the retrieval errors that is not obtained by looking at the errors averaged across all CTH and/or IOT. In Sect. 4.6 the noise sensitivity of CiPS is quantified by comparing the standard retrieval of CiPS with randomly perturbed SEVIRI input data. Finally the results are summarised and discussed in the concluding section. A list of abbreviations is available in Appendix A.

\section{Instruments and data}

\subsection{SEVIRI}

The SEVIRI imager operates aboard the geostationary Meteosat Second Generation (MSG) satellites. SEVIRI measures the up-welling radiation within 12 wavelength intervals (channels) in the visible to thermal infrared spectrum, from which the radiances, equivalent black body brightness temperatures and reflectances can be derived. SEVIRI has a spatial coverage from approx. $80^{\circ} \mathrm{W}$ to $80^{\circ} \mathrm{E}$ and $80^{\circ} \mathrm{S}$ to $80^{\circ} \mathrm{N}$ (from now on referred to as the SEVIRI disc) and a temporal resolution of $15 \mathrm{~min}$. The spatial coverage of SEVIRI can be seen in Fig. 2. Limiting the spatial coverage to latitudes north of approx. $15^{\circ} \mathrm{N}$, the temporal resolution can be increased to $5 \mathrm{~min}$ using the rapid scanning service. The spatial sampling of SEVIRI is $3 \mathrm{~km}$ at nadir for all channels except the highresolution visible channel that has a spatial sampling of $1 \mathrm{~km}$ (Schmetz et al., 2002).

Estimates of the radiometric noise levels of the SEVIRI thermal channels can be derived from measurements of the internal black body calibration target and are reported as noise-equivalent temperature differences $(\mathrm{NE} \Delta T)$ at given reference temperatures in EUMETSAT (2007) and summarised in Table 1 (second column) for all channels (first column) used by CiPS (see Sect. 3.2). As the reference temperatures reported by EUMETSAT are higher than typical bright-
Table 1. Radiometric noise estimates of MSG-2/SEVIRI thermal channels (first column, including the channel centre wavelength $\lambda_{c}$ ) at the reported reference brightness temperatures (second column; EUMETSAT, 2007) and at typical brightness temperatures observed for cirrus cloud retrievals (third column, see Sect. 4.6.1)

\begin{tabular}{lrl}
\hline$\lambda_{\mathrm{c}}(\mu \mathrm{m})$ & \multicolumn{3}{c}{$\mathrm{NE} \Delta T(\mathrm{~K})$} \\
\hline 6.2 & $0.05 @ 250 \mathrm{~K}$ & $0.11 @ 225 \mathrm{~K}$ \\
7.3 & $0.05 @ 250 \mathrm{~K}$ & $0.07 @ 237 \mathrm{~K}$ \\
8.7 & $0.075 @ 300 \mathrm{~K}$ & $0.15 @ 252 \mathrm{~K}$ \\
10.8 & $0.07 @ 300 \mathrm{~K}$ & $0.12 @ 253 \mathrm{~K}$ \\
12.0 & $0.10 @ 300 \mathrm{~K}$ & $0.16 @ 251 \mathrm{~K}$ \\
13.4 & $0.205 @ 270 \mathrm{~K}$ & $0.27 @ 239 \mathrm{~K}$ \\
\hline
\end{tabular}

ness temperatures observed by SEVIRI for cirrus-covered pixels, the third column shows the estimated radiometric noise scaled to reference brightness temperatures representing typical cirrus cloud retrievals (see Sect. 4.6.1). Please note that the reported noise levels are estimators/indicators and not necessarily representative for any given SEVIRI observation. For a statistical analysis, however, those estimates are sufficient.

\subsection{CALIOP}

The CALIOP lidar observes the Earth from a polar orbit aboard CALIPSO. CALIOP emits 20 laser pulses per second and measures curtains of attenuated backscatter profiles along the satellite track with a vertical resolution of up to $30 \mathrm{~m}$ (Winker et al., 2009). In this study we use the version 3 (V3) CALIOP L2 cloud and aerosol layer data at a spatial resolution of $5 \mathrm{~km}$ (CAL_LID_L2_05kmClALay-Prov-V30X; CALIPSO Science Team, 2015a, b, c, d). The layer products provide the vertical position of cloud and aerosol layers in the atmosphere, as well as cloud phase, optical thickness, partial column ice water path and opacity. The opacity is reported as a binary flag and tells whether CALIOP was able to fully penetrate the layer (transparent) or not (opaque).

\subsection{Collocation dataset}

For this study (Sect. 4.3-4.6) we use a dataset of collocated CiPS input data (SEVIRI, ECMWF and auxiliary data; see Sect. 3.2) and cirrus properties retrieved by CALIOP (CTH, IOT, IWP and opacity information), allowing us to apply CiPS and compare the retrievals with the corresponding reference retrievals by CALIOP. The cirrus properties retrieved by CALIOP have been collocated with the SEVIRI observations from the pixel having the largest overlap with the $5 \mathrm{~km}$ CALIOP orbit segment. Due to the different viewing geometries of SEVIRI and CALIOP, the latitude, longitude and cloud top altitude from CALIOP were used to project cirrus clouds to the SEVIRI grid (parallax correction). This dataset was originally used to validate CiPS and contains 5 
million collocations collected over a time period of almost 6 years (April 2007 to January 2013). This represents a random subset containing $10 \%$ of all quality-screened collocations of CiPS input data and CALIOP cirrus cloud properties obtained during this time period. The remaining $90 \%$ of the collocations were used to develop and train CiPS. Hence, the collocation dataset, as well as the training datasets used to develop CiPS, does to some extent (limited by the synsynchronous orbit of CALIPSO) represent the natural distribution of cirrus clouds and cirrus cloud properties. A detailed description of the collocation dataset can be found in Strandgren et al. (2017), where it is referred to as the internal validation dataset.

\section{The CiPS algorithm}

To improve the readability of the paper, ANNs and the CiPS algorithm are shortly introduced.

\subsection{Artificial neural networks}

An ANN is a mathematical model that can be trained to recognise patterns and model functions. A set of multilayer perceptrons (MLPs), a feed-forward artificial neural network, is used by CiPS for the remote sensing of cirrus clouds and is thus shortly introduced here. The goal of an ANN is to model the relationship between two sets of data, such that a vector of output data can be accurately estimated using the information from a vector of known input data. An MLP consists of a number of neurons that exchange information with each other. The neurons are distributed over three major units: (1) the input layer that holds as many neurons as input variables, (2) the output layer that holds as many neurons as output variables and (3) the hidden layers that hold an arbitrary number of hidden neurons distributed over a number of hidden layers. The output value of a neuron is calculated by processing the output from all neurons in the preceding layer connected to that neuron and the corresponding numeric weights assigned to each neuron-neuron connection through an activation function. Hence the only information available to solve a problem is the input data and all connection weights. Thus it is crucial that the weights are assigned correct values.

The weights are tuned by training the ANN. Using the back-propagation algorithm (Rumelhart et al., 1986), as is the case for CiPS, the weights are tuned by looking at a large number of training examples, where both the input data and the corresponding output data are known. The ANN uses the training input data and the current weights to calculate a vector of output data. The skill of the ANN is determined by calculating the squared error between the vector of estimated output data and the corresponding vector of known reference output data. The squared error is then propagated backwards through the ANN and each weight is tuned such that the error is minimised. The training procedure is an iterative process and continues until the error between estimation and reference is sufficiently low.

\subsection{CiPS}

The CiPS algorithm (details in Strandgren et al., 2017) detects cirrus clouds, identifies opaque pixels and retrieves the corresponding CTH, IOT and IWP. To this end a set of four ANNs is used, trained with MSG-2/SEVIRI thermal observations, the surface skin temperature $T_{\text {surf }}$ (from ECMWF) and auxiliary data as input and V3 CALIOP L2 layer data (CALIPSO Science Team, 2015a, b, c, d) as reference output data. CiPS uses one ANN to derive a cirrus cloud flag (CCF) that classifies the SEVIRI pixels as either cirrus-free or cirrus-covered. This ANN has been trained to identify pixels, in which CALIOP did detect icy cloud layers. A second ANN is used for the CTH retrieval and a third ANN for the IOT and IWP retrieval. The fourth ANN is used to derive an opacity flag (OPF) that classifies the cirrus-covered pixels as either transparent or opaque. As CALIOP becomes saturated for optically thicker cirrus (IOT $\gtrsim 3$ ), the CiPS IOT and IWP retrievals should not be trusted in such situations. Thus the OPF is trained to distinguish between the cirrus clouds that could be fully penetrated by CALIOP (transparent cirrus) and those that could not (opaque cirrus).

CiPS input data selection is based on physical considerations. CiPS works pixel by pixel and uses the single brightness temperatures from the SEVIRI channels centred at 6.2, $7.3,8.7,10.8,12.0$ and $13.4 \mu \mathrm{m}$. Water vapour channels (centred at 6.2 and $7.3 \mu \mathrm{m}$ ) should help detecting ice clouds (see e.g. Krebs et al., 2007), identifying opaque pixels as well as determining its height, together with the $\mathrm{CO}_{2}$ channel centred at $13.4 \mu \mathrm{m}$ (e.g. Menzel et al., 1983; Schmetz et al., 1993). Window channels $(8.7,10.8,12.0 \mu \mathrm{m})$ and especially their brightness temperature differences are both useful for detection (e.g. Inoue, 1985) and for the optical thickness determination (e.g. Ackerman et al., 1990). Furthermore, CiPS exploits the information from nearby SEVIRI pixels by utilising the regional maximum brightness temperature from the window channels (for all ANNs, as a proxy for cirrus-free conditions) and the regional average brightness temperature from the water vapour channels (only for cirrus detection and opacity classification, as a proxy for the smoothness of the surroundings). The regional maximum brightness temperature is defined as the maximum brightness temperature within a $19 \times 19$ pixels large box (corresponding to an area of $\approx 57 \times 57 \mathrm{~km}^{2}$ at nadir) centred at the pixel under consideration. Similarly the regional average brightness temperature is defined as the boxcar average temperature within the same box (inspired by Krebs et al., 2007). The modelled surface temperature from ECMWF provides a cirrus-free characterisation of the surface and should be useful in all ANNs. Finally, CiPS uses the latitude, the viewing zenith angle of SEVIRI, two surface type flags (seawater and permanent ice and snow) and the day of the year (DOY, 1-365; to avoid 
a hard transition from 31 December to 1 January, two input neurons are used for the DOY: $\sin (2 \pi \mathrm{DOY} / 365)$ and $\cos (2 \pi \mathrm{DOY} / 365))$. Latitude and day of year are selected since the appearance of cirrus and their top height strongly depends on general circulation and convection strength, with higher clouds in the tropics and generally lower clouds towards the polar regions and with stronger convection in summer with respect to spring/autumn and, of course, winter in mid-latitudes. Viewing angle shall account for the path length of radiation through the atmosphere, while the two selected surface types identify on one side (sea) thermally quite homogeneous surfaces and on the other side (ice/snow) cold surfaces with similar absorption properties as the ice clouds. In total, 18 input variables are used for the cirrus detection and opacity classification and 16 input variables for the $\mathrm{CTH}$, IOT and IWP retrieval (please see Table 2 in Strandgren et al., 2017, for a tabular overview of all input variables). Although the selection of input quantities is inspired by physical principles, the task of combining input variables is left to the ANN.

In the following, all quantities referring to CiPS will be denoted as $\mathrm{CCF}_{\mathrm{CiPS}}, \mathrm{OPF}_{\mathrm{CiPS}}, \mathrm{CTH}_{\mathrm{CiPS}}$, $\mathrm{IOT}_{\mathrm{CiPS}}$ and $\mathrm{IWP}_{\mathrm{CiPS}}$, while all quantities referring to CALIOP will be denoted as $\mathrm{CTH}_{\text {CALIOP }}$, IOT $_{\text {CALIOP }}$ and IWP CALIOP

\section{Characterisation of CiPS}

Strandgren et al. (2017) present the CiPS retrieval accuracy for cirrus detection, opacity classification and for the derivation of the physical and optical properties CTH, IOT and IWP with respect to CALIOP. In the present paper, a more differentiated investigation is performed that aims at characterising the ANNs according to various aspects. First, despite the fact that CiPS input quantities have been selected according to physical principles (see Sect. 3.2), it is unclear which importance the single input variables have been assigned by the ANNs. This a posteriori examination also gives hints about the ability of the ANNs to model physical relationships among the variables. Second, the combination of cirrus products from visible backscattered vertically resolved "monochromatic" lidar radiation (CALIOP) and thermal "columnar" narrowband brightness temperatures from imager channels (SEVIRI) is supported by the knowledge that cirrus clouds leave their mark on both measurements types in a "similar" way: for instance, both methods are sensitive to visible ice optical thickness up to ca. 5 (e.g. DeSlover et al., 1999). Nevertheless, CALIOP's possibility of discerning vertical features (ice clouds, liquid water clouds, aerosols) is not shared by SEVIRI, which poses the question whether the proposed CALIOP-SEVIRI synergy is always meaningful. To clarify this aspect, the CiPS performance is investigated for various vertical arrangements of cloud and aerosol layers and for various surface types. Furthermore, cirrus clouds are classified according to their IOT
Table 2. Contingency table for the cirrus detection from CALIOP and CiPS.

\begin{tabular}{clcc}
\hline & & \multicolumn{2}{c}{ CALIOP } \\
\cline { 3 - 3 } & & Cirrus & No cirrus \\
\hline \multirow{2}{*}{ CiPS } & Cirrus & $N_{\mathrm{TP}}$ & $N_{\mathrm{FP}}$ \\
& No cirrus & $N_{\mathrm{FN}}$ & $N_{\mathrm{TN}}$ \\
\hline
\end{tabular}

and $\mathrm{CTH}$ to provide a better understanding of the CiPS retrieval errors (magnitude and bias). Finally, the sensitivity to radiometric noise in the SEVIRI data is quantified.

\subsection{Validation metrics}

First of all, the validation metrics used in the following are presented.

The probability of detection (POD) is used to measure how efficiently CiPS detects cirrus clouds and is given by

$\mathrm{POD}=\frac{N_{\mathrm{TP}}}{N_{\mathrm{TP}}+N_{\mathrm{FN}}}$,

where the number of true positives, $N_{\mathrm{TP}}$, are all points correctly classified as cirrus and the number of false negatives, $N_{\mathrm{FN}}$, all cirrus clouds that remain undetected. The denominator, $N_{\mathrm{TP}}+N_{\mathrm{FN}}$, is thus the total number of points with a reference cirrus cloud. The false alarm rate (FAR) measures the fraction of cirrus-free points that are falsely classified as being cirrus clouds and is given by

$\mathrm{FAR}=\frac{N_{\mathrm{FP}}}{N_{\mathrm{FP}}+N_{\mathrm{TN}}}$,

where the number of false positives, $N_{\mathrm{FP}}$, are all points falsely classified as cirrus (false alarms) and the number of true negatives, $N_{\mathrm{TN}}$, all points correctly identified as cirrusfree. The denominator, $N_{\mathrm{FP}}+N_{\mathrm{TN}}$, is thus the total number of points with no reference cirrus cloud. The corresponding CALIOP data are used as a reference when calculating the POD and FAR. Table 2 clarifies the quantities used to calculate the POD and FAR.

The mean absolute percentage error (MAPE) and mean percentage error (MPE) are defined as

$$
\begin{aligned}
& \text { MAPE }=\frac{100 \%}{N} \sum_{i=1}^{N}\left|\frac{E_{i}-O_{i}}{O_{i}}\right|, \\
& \mathrm{MPE}=\frac{100 \%}{N} \sum_{i=1}^{N} \frac{E_{i}-O_{i}}{O_{i}},
\end{aligned}
$$

where $O_{i}$ is the observed reference value retrieved by CALIOP and $E_{i}$ the estimated value by CiPS. The sum spans over all samples $i=1, \ldots, N$ used for the evaluation. The MAPE gives information about the average magnitude of the CiPS retrieval errors relative to the expected reference value 
retrieved by CALIOP. The MPE gives information about the direction of the deviations, i.e. whether CiPS tends to overestimate (positive MPE) or underestimate (negative MPE) the values with respect to CALIOP (bias). When calculating the MPE, over- and underestimates can cancel out each other, potentially leading to zero MPE/bias even if the magnitude of the errors is large. Therefore the MAPE has been considered as well.

\subsection{Relative importance of the CiPS input data}

To understand, improve and extend CiPS and similar ANNbased retrieval algorithms, it is valuable to understand what input data have essential contributions to the solution of a given problem. Important input variables are identified by the ANN and given a strong weight during the training. Similarly, less important input variables are given a weaker weight and thus a smaller role in retrieving the output data.

The importance of an input variable can be estimated as the euclidean length of the vector holding all weights that connect that input neuron with the hidden neurons in the first hidden layer (LeCun et al., 1990). The importance (or total weight) of an input variable $i$ is thus calculated as $W_{i}=\sqrt{w_{i, 1}^{2}+w_{i, 2}^{2}+\ldots+w_{i, N}^{2}}$, where $w_{i, 1}$ to $w_{i, N}$ are the single weights connecting input variable $i$ with the $N$ neurons in the first hidden layer. Figure 1 shows the relative importance of the 18 input variables used by CiPS. The relative importance of all input variables is calculated as $W_{i}^{*}=100 \% \times W_{i} /\left(W_{1}+W_{2}+\ldots+W_{18}\right)$ for the respective ANNs such that the sum of the relative importance across all input variables adds up to $100 \%$ for each ANN. The four columns represent the four ANNs. No relative importance of the regional average brightness temperatures is reported for

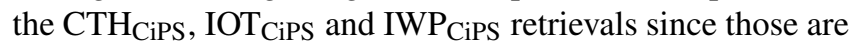
used exclusively for the cirrus detection and opacity classification (see Sect. 3.2).

It is clear that the window channels of SEVIRI are essential for the detection and opacity classification of cirrus clouds as well as for the determination of IOT $_{\mathrm{CiPS}}$ and

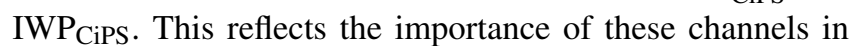
physically based retrievals (e.g. Ewald et al., 2013; Heidinger et al., 2015; Iwabuchi et al., 2016). For the $\mathrm{CTH}_{\mathrm{CiPS}}$ retrieval, the latitude is the dominant input variable, followed by the water vapour channels. Similarly the DOY has a comparably strong importance for the $\mathrm{CTH}_{\mathrm{CiPS}}$ retrieval. The relative importance of $\mathrm{BT}_{13.4 \mu \mathrm{m}}$ is surprisingly low for the $\mathrm{CTH}_{\mathrm{CiPS}} \mathrm{re}-$ trieval, although observations from around $13.4 \mu \mathrm{m}$ are commonly used by the $\mathrm{CO}_{2}$-slicing method for CTH retrievals (e.g. Menzel et al., 2008). This is a hint that the ANN may model a statistical, rather than physical, relationship between the input and output variables, as the CTH has an annual cycle and a clear latitude dependency (Stubenrauch et al., 2013). It might also be that the $13.4 \mu \mathrm{m}$ brightness temperature only provides redundant information with respect to
Relative input variable importance / \%

\begin{tabular}{|c|c|c|c|c|}
\hline $\mathrm{BT}_{6.2 \mu \mathrm{m}}$ & 3.0 & 4.4 & 8.4 & 5.1 \\
\hline $\mathrm{BT}_{7.3 \mu \mathrm{m}}$ & 7.5 & 11.2 & 11.5 & 10.7 \\
\hline $\mathrm{BT}_{8.7 \mu \mathrm{m}}$ & 10.1 & 18.6 & 6.0 & 11.7 \\
\hline $\mathrm{BT}_{10.8 \mu \mathrm{m}}$ & 13.5 & 14.7 & 3.3 & 12.7 \\
\hline $\mathrm{BT}_{12.0 \mu \mathrm{m}}$ & 18.0 & 9.0 & 9.7 & 15.0 \\
\hline $\mathrm{BT}_{13.4 \mu \mathrm{m}}$ & 4.3 & 7.4 & 6.8 & 5.3 \\
\hline $\mathrm{BT}_{6.2 \mu \mathrm{mm}}^{\text {regang }}$ & 3.6 & 3.4 & - & - \\
\hline $\mathrm{BT}_{7.3 \mathrm{\mu m}}^{\text {regang }}$ & 7.6 & 4.6 & - & - \\
\hline $\mathrm{BT}_{8.7 \mathrm{~mm}}^{\text {regmax }}$ & 4.1 & 4.2 & 4.4 & 6.1 \\
\hline $\mathrm{BT}_{10.8 \mu \mathrm{m}}^{\text {regmax }}$ & 6.3 & 6.2 & 4.1 & 4.4 \\
\hline $\mathrm{BT}_{12.0 \mu \mathrm{m}}^{\text {regmax }}$ & 7.8 & 5.7 & 5.5 & 7.9 \\
\hline$T_{\text {surf }}$ & 2.0 & 2.2 & 5.3 & 5.4 \\
\hline Latitude & 4.4 & 1.4 & 18.1 & 4.9 \\
\hline VZA & 2.6 & 3.0 & 6.6 & 4.7 \\
\hline Water flag & 0.4 & 1.7 & 1.7 & 1.1 \\
\hline Snow/ice flag & 4.0 & 1.6 & 2.3 & 3.5 \\
\hline DOY $_{\text {SIN }}$ & 0.2 & 0.5 & 1.9 & 0.4 \\
\hline $\mathrm{DOY}_{\cos }[$ & 0.6 & 0.4 & 4.5 & 1.0 \\
\hline
\end{tabular}

Figure 1. Relative importance of the CiPS input variables (vertical axis) for the four ANNs (horizontal axis). The blue shades further highlight the magnitude of the relative importance with fading colours for decreasing importance. BT is brightness temperature, regavg is regional average, regmax is regional maximum and VZA is viewing zenith angle. DOY $\mathrm{SIN}=\sin (2 \pi \mathrm{DOY} / 365)$ and DOY $_{\mathrm{COS}}=\cos (2 \pi \mathrm{DOY} / 365)$.

cloud top height since also water vapour channels and surface skin temperatures are available to the ANN (see discussion about the physical motivation of the input variables in Sect. 3.2). For the $\mathrm{CCF}_{\mathrm{CiPS}}$, $\mathrm{OPF}_{\mathrm{CiPS}}$, IOT $\mathrm{CiPS}$ and $\mathrm{IWP}_{\mathrm{CiPS}}$ retrievals, the DOY has a very low importance and consequently a minor contribution to the retrievals. The surface temperature from the model is clearly helpful for determining the $\mathrm{CTH}_{\mathrm{CiPS}}$, IOT $\mathrm{CiPS}$ and IWP $\mathrm{IPPS}_{\mathrm{C}}$. The information about whether the Earth's surface is covered by permanent ice or snow is valuable for the cirrus detection as well as the IOT $_{\mathrm{CiPS}}$ and IWP $_{\mathrm{CiPS}}$ retrievals, whereas the surface water flag has a comparably small contribution to the retrievals. Exploiting the information from nearby SEVIRI pixels using the regional maximum and regional average temperatures is clearly helpful in all aspects; their relative importance is comparable to the relative importance of $T_{\text {surf }}$ for the

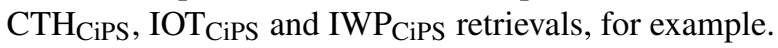




\subsection{The CiPS retrieval accuracy for different surface types}

In this section the performance of CiPS is characterised with respect to a set of five surface type classes extracted from MODIS L3 data. For this section as well as for the remainder of this paper (except the noise sensitivity analysis in Sect. 4.6) the performance of CiPS is always evaluated with respect to the cirrus cloud retrievals by CALIOP.

\subsubsection{Surface type classes from MODIS}

The International Geosphere-Biosphere Programme (IGBP; Loveland and Belward, 1997) has defined 17 land surface types including 11 natural vegetation classes, 3 developed and mosaicked land classes and 3 non-vegetated land classes. The MODIS L3 product MCD12C1 (Friedl et al., 2010) provides the majority land cover type at a resolution of $0.05^{\circ}$ according to the IGBP classification. The MCD12C1 V051 dataset for 2012 has first been reprojected to the SEVIRI grid using the nearest neighbour method. Then, for the characterisation of CiPS with respect to the underlying surface type, the different surface classes have been grouped into the five following classes: (1) water including ocean, lakes, rivers and wetlands; (2) barren including surfaces covered by soil, sand and rocks with a maximum vegetation of $10 \%$; (3) permanent ice and snow including surfaces permanently covered by ice and/or snow; (4) forest including all surfaces dominated by trees (canopy cover $>60 \%$ ); and (5) vegetation excluding forest including all surfaces with other types of vegetation i.e. shrublands, savannahs, grasslands and croplands. Detailed information about the IGBP surface types can be found in Loveland and Belward (1997). These surface types are expected to have different spectral properties and humidity contents that might affect the thermal SEVIRI channels (Sect. 3.2) and therefore the CiPS ANNs. The geographical coverage of the five surface classes used in this study is visualised in Fig. 2. Please note that the barren class is composed mostly of bright desert surfaces in the SEVIRI disc. Hence the results presented for barren in this section are mostly representative for retrievals over desert and only to a very limited extent for retrievals over other types of barren present in e.g. the Andes and Iceland. Permanent ice and snow is only found in Greenland, Antarctica, and to a limited extent in high mountain ranges.

\subsubsection{Cirrus cloud detection}

The $\mathrm{CCF}_{\mathrm{CiPS}}$ is evaluated as a function of the underlying surface type using the POD (Eq. 1) and the FAR (Eq. 2). To avoid the presence of (liquid water cloud/aerosol) layers between cirrus and surface that would shield radiation emitted by the surface, the CALIOP L2 data are used to identify and include only those profiles with clear air (at most a faint aerosol layer with aerosol optical thickness AOT $\leq 0.2$ ) be-

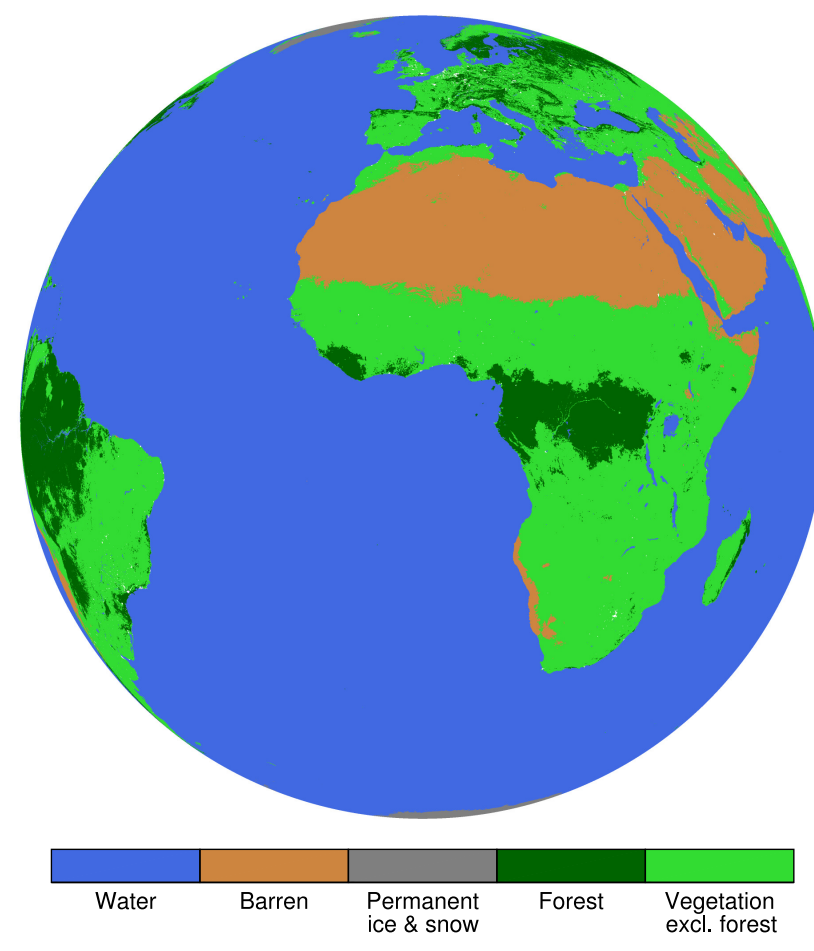

Figure 2. Visualisation of the geographical coverage of the five surface type classes across the SEVIRI disc.

low a possible transparent cirrus cloud in the analysis (see class C1 (for POD) and class C7 (for FAR) in Sect. 4.4.1 and Fig. 5). In total approx. 600000 such collocations are available in the collocation dataset, with the largest number of occurrences over water (360000) and the smallest number over barren (36 000). The goal of the OPF retrieved by CiPS is to detect cirrus clouds that are opaque, i.e. where the vertical structure below the cirrus is unknown for CiPS/CALIOP. Consequently, the OPF of CiPS is not characterised for the different surface types as it cannot be ruled out that there are no liquid water clouds or aerosol layers with AOT $>0.2$ below an opaque cirrus. Please note that the more accurate OPF of CALIOP is used to identify profiles with opaque cirrus clouds that are excluded from the analysis as explained in Sect. 4.4.1. Also note that the terms "transparent" and "opaque" in this context are solely related to the saturation of the CALIOP laser beam and tell whether it was able to fully penetrate the cirrus cloud (transparent cirrus) or not (opaque cirrus).

Figure 3 shows the POD of CiPS for the five surface type classes. The POD is presented as a function of IOT $_{\text {CALIOP. }}$ For a better visualisation of thin cirrus, the scale is logarithmic for IOT $_{\text {CALIOP }}<1.0$ and linear for IOT $_{\text {CALIOP }} \geq 1.0$. As a reference, the average POD for all surface types is included (black line). We require a lower limit of 10 samples for the statistics, so no POD over barren is available for thicker cirrus clouds (IOT CALIOP $\gtrsim 3.0$ ). The same is done for the remainder of this paper. 


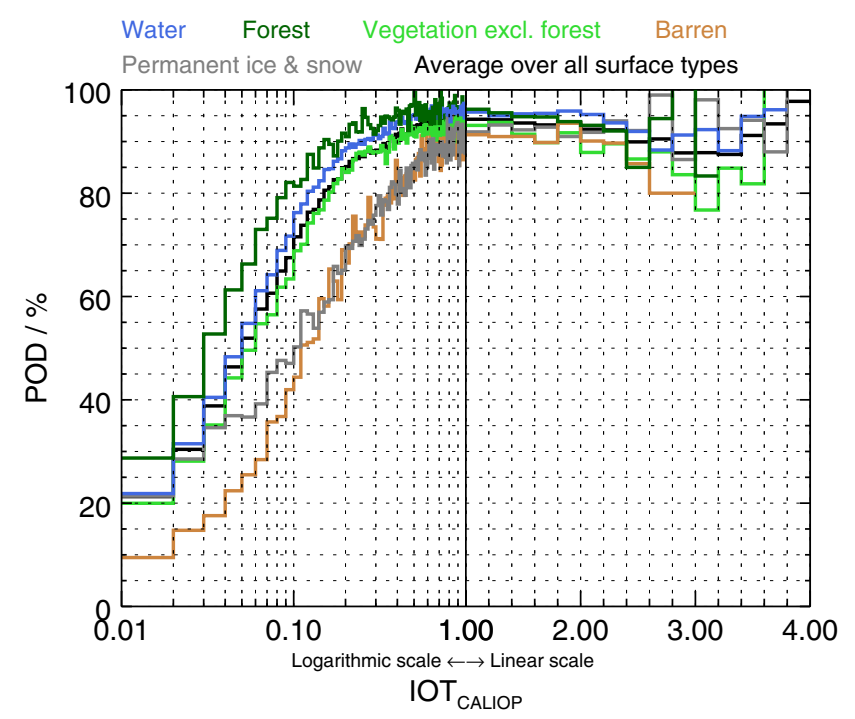

Figure 3. The cirrus POD of CiPS as a function of the IOT retrieved by CALIOP for the five surface type classes. Note that the line colours correspond to the colours used in Fig. 2.

CiPS has a clearly lower POD over barren and permanent ice and snow for cirrus clouds with IOT $_{\text {CALIOP }} \lesssim 0.5$ : up to $20 \%$ less cirrus clouds are detected than on average. Both are known to be difficult (cirrus) cloud retrieval conditions (Frey et al., 2008; Holz et al., 2008). Over ice and snow the radiative contrast between the cirrus and the cold surface is reduced, making the cirrus cloud detection more difficult. Furthermore, mixed-phase clouds or supercooled liquid water layers above ice layers in the polar regions (Mioche et al., 2015; Verlinde et al., 2007; Shupe et al., 2006) may also reduce the POD as CiPS requires the water to be frozen to be classified as a cirrus. Moreover, temperature inversions, frequent in these areas (Wetzel and Brümmer, 2011), can make the cloud top of low ice clouds (Devasthale et al., 2011) appear warmer than the snow/ice-covered surface and thus reduce their detection (Wilson et al., 1993; Gao et al., 1998). Finally, the retrieval conditions over Greenland and Antarctica are the least favourable ones for SEVIRI, with the largest viewing zenith angles and pixel sizes. The FAR over permanent ice and snow is $4.3 \%$, which is higher than the average FAR of $3.2 \%$ over all surface types. Barren is to a large extent made up by deserts, where cirrus clouds rarely form, yet they can be found there when they drift towards midlatitudes after formation in the Intertropical Convergence Zone (ITCZ). The ANN is likely to learn such a pattern of low occurrence frequency and thus miss more thin cirrus in those regions. This is supported by the fact that the FAR is lowest over barren, where only $1.1 \%$ of the cirrus-free cases are falsely classified as cirrus. The highest POD is observed over forest: up to $15 \%$ more than on average for IOT $_{\text {CALIOP }}$ up to 0.5 . This is due to the high cirrus cloud occurrence over the tropical rainforests that increases the POD in a sim- ilar manner as the POD is reduced over barren. Again this is supported by the highest FAR of $7.1 \%$ over forest. Similar trends could be seen in Fig. 5 in Strandgren et al. (2017), with the minimum FAR over the Sahara and the maximum FAR above the African and South American rainforests. Water and other vegetation (vegetation excluding forest) have similar POD, but the cirrus detection is slightly better over homogeneous water surfaces than over vegetation excluding forest. The corresponding FARs are $3.1 \%$ over water and $3.5 \%$ over vegetation excluding forest. Notice finally that due to their large number over the SEVIRI disc the water pixels dominate the average curve.

\subsubsection{Cirrus cloud properties}

Figure 4 shows the MAPE and MPE for the (a) $\mathrm{CTH}_{\mathrm{CiPS}}$, (b) IOT $_{\text {CiPS }}$ and (c) IWP $_{\text {CiPS }}$ retrievals as functions of the corresponding reference retrievals by CALIOP and the five surface type classes. Within each $\mathrm{CTH}_{\mathrm{CALIOP}}, \mathrm{IOT}_{\mathrm{CALIOP}}$ and

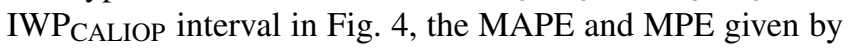
Eq. (3a) and (3b) is calculated. Please note that the results are presented with a logarithmic scale for IOT $_{\text {CALIOP }}<1.0$ and IWP CALIOP $<10.0 \mathrm{~g} \mathrm{~m}^{-2}$ and with a linear scale for $\mathrm{IOT}_{\text {CALIOP }} \geq 1.0$ and IWP $\mathrm{CALIOP} \geq 10.0 \mathrm{~g} \mathrm{~m}^{-2}$. The average MAPE and MPE (bias) over all surface type classes are included as reference. Again, we only consider profiles with clear air (no liquid water clouds and AOT $\leq 0.2$ ) below the cirrus cloud.

Mostly the same patterns of the MAPE and MPE are observed as in Strandgren et al. (2017), namely that CiPS tends to overestimate the CTH for low cirrus/ice clouds and slightly underestimate the CTH for high cirrus. Similarly the IOT and IWP is predominantly over- and underestimated for the lower and upper extreme values respectively.

Overall, the $\mathrm{CTH}_{\mathrm{CiPS}}$ retrieval is mostly insensitive to the underlying surface type for $\mathrm{CTH}_{\text {CALIOP }}>8.0 \mathrm{~km}$. A stronger underestimation of $\mathrm{CTH}_{\mathrm{CALIOP}}(20-40 \%)$ is, however, observed over permanent ice and snow for high cirrus clouds $\left(\mathrm{CTH}_{\text {CALIOP }}>12 \mathrm{~km}\right)$. Those are cirrus/ice clouds that extend into the stratosphere. We observe a stronger tendency for underestimations also for lower clouds over permanent ice and snow. For the lowermost cirrus clouds, the $\mathrm{CTH}_{\mathrm{CiPS}}$ retrieval is best over permanent ice and snow. This is most likely due to the fact that the average $\mathrm{CTH}$ is lowest in the polar regions, making it easier for the ANN to model and estimate the CTH for low cirrus/ice clouds there. In contrast, barren, forest and vegetation excluding forest do, to a large extent, cover regions where the $\mathrm{CTH}$ is typically higher, making it more difficult to model and estimate the $\mathrm{CTH}$ for low cirrus. Over desert, where the air is dry, it is plausible that the signal from the water vapour channels (which were shown to have strong relative importance for the $\mathrm{CTH}_{\mathrm{CiPS}}$ retrieval in Sect. 4.2) peak at lower altitudes in the atmosphere compared to more moist regions, resulting in biases for the CTH retrieval over barren. On av- 

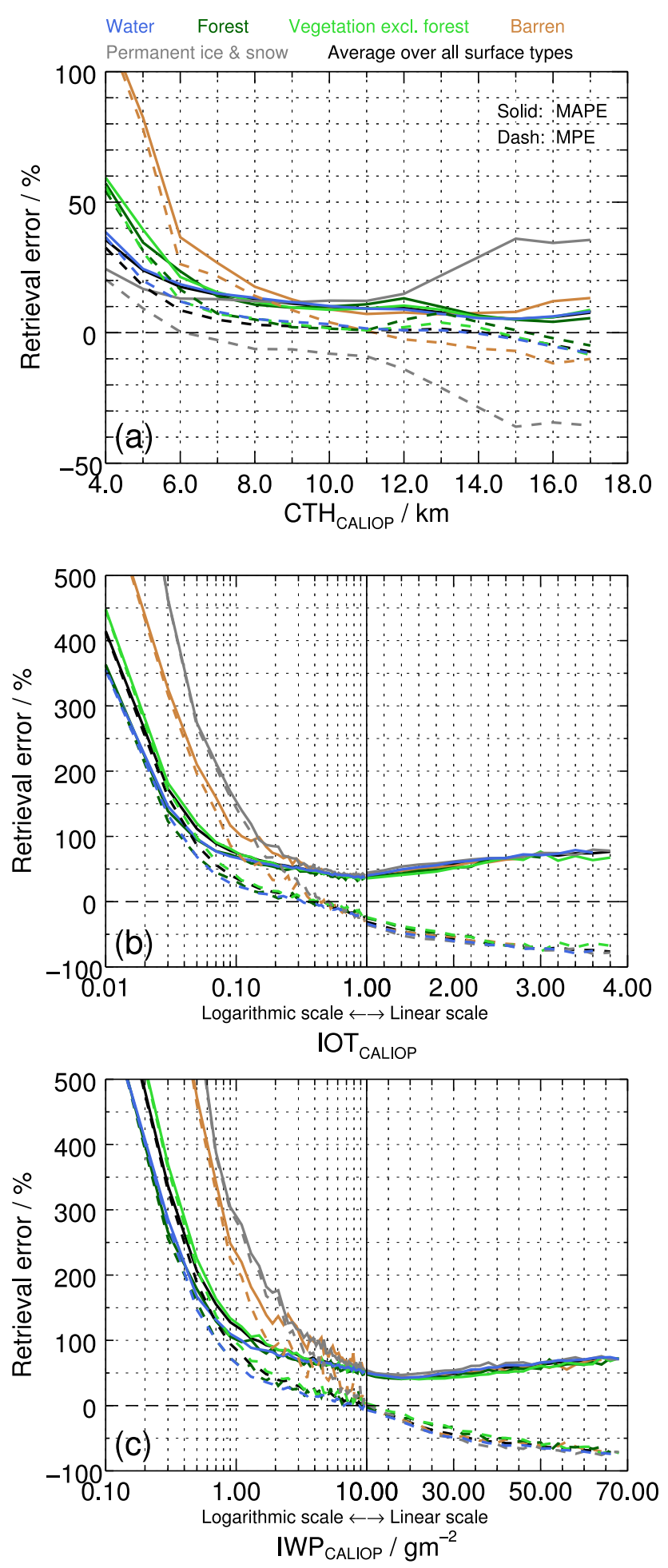

Figure 4. The MAPE (solid) and MPE (dash) of the $\mathrm{CTH}_{\mathrm{CiPS}}$ (a), IOT $_{\mathrm{CiPS}}(\mathbf{b})$ and $\mathrm{IWP}_{\mathrm{CiPS}}(\mathbf{c})$ retrievals as functions of the corresponding reference retrievals from CALIOP. The retrieval errors of CiPS are presented for the five surface type classes introduced in Sect. 4.3.1. erage the CTH is estimated with the lowest MAPE and bias over homogeneous water surfaces.

The underlying surface type has a similar effect on the IOT $_{\mathrm{CiPS}}$ retrieval as on the $\mathrm{IWP}_{\mathrm{CiPS}}$ retrieval. This

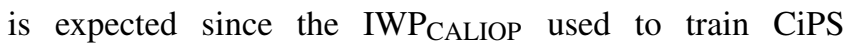
is parametrised from the CALIOP extinction coefficients (Heymsfield et al., 2005) from which IOT $_{\text {CALIOP }}$ is directly derived. For IOT $_{\text {CALIOP }}>0.5$ and IWP $_{\text {CALIOP }}>$ $10.0 \mathrm{~g} \mathrm{~m}^{-2}$, the underlying surface type has no effect on the $\mathrm{IOT}_{\mathrm{CiPS}} / \mathrm{IWP}_{\mathrm{CiPS}}$ retrievals; i.e. already for these low values of $\mathrm{IOT}_{\mathrm{CALIOP}} / \mathrm{IWP}_{\mathrm{CALIOP}}$ are the characteristics of surface radiation negligible. For thinner cirrus clouds the retrieval errors increase substantially over permanent ice and snow. This should be related to the effects discussed above, namely the reduced radiative contrast of the cirrus above cold snow and ice and the unfavourable conditions for SEVIRI in the polar regions. $\mathrm{IOT}_{\mathrm{CiPS}} / \mathrm{IWP}_{\mathrm{CiPS}}$ retrievals over barren are also less certain for thin cirrus clouds. Deserts are characterised by a lower emissivity at $8.7 \mu \mathrm{m}$ than at 10.8 or $12.0 \mu \mathrm{m}$ (e.g. Hulley et al., 2015; De Paepe and Dewitte, 2009; Trigo et al., 2008). It is possible that this induces larger $\mathrm{IOT}_{\mathrm{CiPS}} / \mathrm{IWP}_{\mathrm{CiPS}}$ retrieval errors because the ANN cannot localise desert regions unambiguously using only latitude and viewing zenith angle. The retrieval errors over vegetation excluding forest are close or identical to the average performance for all IOT CALIOP $_{\text {and IWP }}$ CALIOP. The lowest $\mathrm{IOT}_{\mathrm{CiPS}}$ and $\mathrm{IWP}_{\mathrm{CiPS}}$ retrieval errors are again obtained over homogeneous water surfaces as well as over forest.

\subsection{The CiPS retrieval accuracy for different vertical cloud-aerosol structures}

In this section the performance of CiPS is characterised with respect to a set of seven vertical cloud-aerosol structure classes derived from the V3 CALIOP L2 layer products. This is important in order to understand the accuracy of the retrievals for different scattering and absorbing atmospheres. Although the OPF already yields quality information indicat-

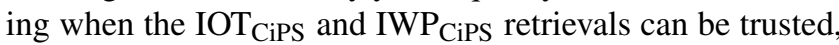
there is still the chance that the passive instrument SEVIRI is not able to deal with all possible vertical arrangements of clouds and aerosols as the active instrument CALIOP does, since SEVIRI lacks the vertical resolution.

The characterisation is performed for all surface types combined. Although the retrieval accuracy shows a dependency on the underlying surface type (Sect. 4.3), the effect of liquid water clouds and aerosol layers below the cirrus cloud has a similar effect on the cirrus cloud retrieval over all underlying surface types (not shown here). The patterns and results obtained for all surface types combined (presented here) are consequently to a large extent representative for the single surface types as well. Due to the large coverage of oceans on the SEVIRI disc (see Fig. 2), the results presented here are, however, more representative for retrievals over water. 
Again, only the CiPS quantities $\mathrm{CCF}_{\mathrm{CiPS}}, \mathrm{CTH}_{\mathrm{CiPS}}$, IOT $_{\text {CiPS }}$ and IWP ${ }_{\text {CiPS }}$ are characterised for the different vertical cloud-aerosol structures. The $\mathrm{OPF}_{\mathrm{CiPS}}$ is excluded from the analysis since its goal is to detect cirrus clouds where the vertical structure below the cirrus cannot be resolved by CALIOP. Opaque cirrus clouds are identified and excluded using the OPF of CALIOP as described in the following section.

\subsubsection{Vertical cloud-aerosol structures from CALIOP}

The collocation dataset presented in Sect. 2.3 and first developed in Strandgren et al. (2017) is extended to characterise the entire atmospheric column observed by CALIOP (and SEVIRI). The column optical thickness and the corresponding top and base heights for aerosol layers, cirrus clouds and liquid water clouds are derived from the CALIOP cloud and aerosol layer products (see Sect. 2.2). The column AOT is read from the "Column_Optical_Depth_Aerosols_532" product contained in the $\mathrm{L} 2$ aerosol layer products. The corresponding top and base heights of the upper and lowermost aerosol layers are read from the "Layer_Base_Altitude" and "Layer_Top_Altitude" products. Finally the opacity information is retrieved from the "Opacity_Flag". For clouds, the column optical thickness is reported for liquid water and ice clouds combined. The cloud properties, including IOT, liquid water optical thickness, the corresponding top and base heights and the opacity information, are instead derived using the same approach used to derive the cirrus cloud properties in Strandgren et al. (2017). In particular, one has to take into account the spatial resolution at which cloud and aerosol layers are detected as well as the possible vertical overlap between layers detected at different spatial resolutions. Notice as well that mixed-phase clouds, i.e. layers where ice and supercooled liquid water coexist, are classified as either liquid, ice or unknown phase clouds by CALIOP. The high confidence criteria imposed to the CALIOP cloud phase (see below) shall, however, constrain the selected cloud and cloud profiles to high confidence liquid and high confidence ice clouds. Nevertheless, especially at high latitudes, an uncertainty remains due to the difficult cloud phase determination (Cesana et al., 2016).

The dataset is carefully quality screened and does only include CALIOP profiles where all feature types and phases were determined with high confidence (QA_flag =3). Furthermore, the quality assessment from Strandgren et al. (2017) is adopted not only for ice clouds but also for liquid water clouds and, especially, for aerosol layers: only constrained or unconstrained retrievals where the initial lidar ratio remained unchanged during the solution process are included (Strandgren et al., 2017).

Using the vertical position, optical thickness and opacity information of all clouds and aerosol layers, the seven vertical cloud-aerosol structure classes listed below are created. In this study we are interested in the effect of thicker aerosol layers on the cirrus cloud retrieval by CiPS. Therefore we only acknowledge aerosol layers with an AOT > 0.2. These aerosols come mainly from desert dust (Weinzierl et al., 2011; Groß et al., 2015) but also from biomass burning (Rosário et al., 2011; Ten Hoeve et al., 2012) or, sometimes, sea salt (Toth et al., 2013). We assume that AOT $\leq 0.2$ is a good approximation for the AOT of typical aerosol loads. In comparison, the rural aerosol model by Shettle (1989) in the boundary layer for spring-summer conditions and a visibility of $50 \mathrm{~km}$ together with background aerosol above $2 \mathrm{~km}$ represent an AOT of 0.162 .

C1 Profiles where only transparent cirrus clouds (and possible aerosols with AOT $\leq 0.2$ ) are observed.

C2 Profiles where cirrus clouds are observed over an aerosol layer with AOT $>0.2$.

C3 Profiles where cirrus clouds are observed above a low opaque liquid water cloud. To ensure that the cirrus is well separated from the water cloud, the vertical distance between the two has to be $4.0 \mathrm{~km}$ or more. This class aims to capture scenes with cirrus clouds over lowlevel clouds. The threshold of $4 \mathrm{~km}$ was chosen such that it is applicable both in the tropical regions as well as at higher latitudes, where the vertical separation between high-level cirrus clouds and low-level clouds is smaller.

C4 Profiles where cirrus clouds are observed vertically close or adjacent to an opaque liquid water cloud. To ensure that the cirrus is close to the water cloud, the vertical distance between the two has to be $0.5 \mathrm{~km}$ or less. This spatial separation value enables to neglect small cloud gaps due to turbulence, evaporation, sedimentation or wind shear inside clouds. This class aims to capture mainly convective clouds with a cirrus shield/anvil.

C5 Profiles where only opaque liquid water clouds are observed. No cirrus clouds are present.

C6 Profiles where only an aerosol layer with AOT $>0.2$ is observed. No clouds are present.

C7 Profiles where only clear sky or aerosols with AOT $\leq 0.2$ are observed. No clouds are present.

Please note that all liquid water clouds were opaque for the CALIOP lidar. Hence there is the possibility of having a thicker aerosol layer below the liquid water clouds. The effect of the aerosol layer is, however, assumed to be negligible due to the use of observations in the infrared spectrum where the liquid cloud is also opaque. This vertical cloudaerosol structure information is extracted and appended to the corresponding collocations contained in the collocation dataset (Sect. 2.3). For a graphical interpretation of the vertical cloud-aerosol structure classification, all classes are visualised in Fig. 5. The number of samples for each class is 


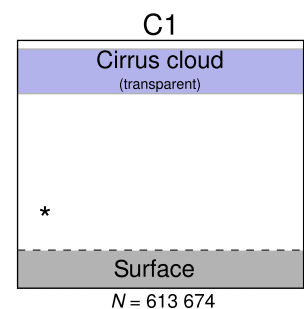

C5
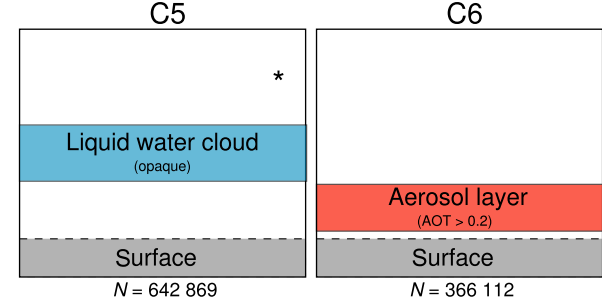

C2

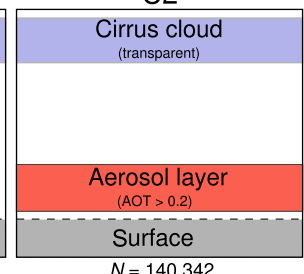

140342

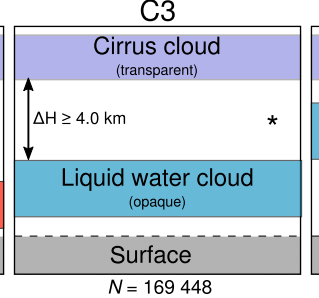

$\mathrm{C} 7$

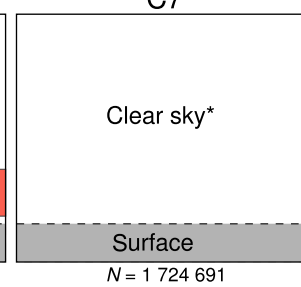

C4

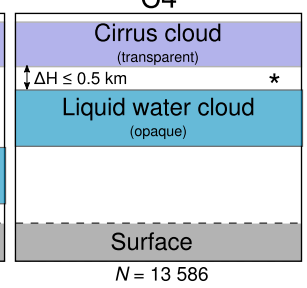

Background levels of aerosol (AOT $\leq 0.2)$ allowed

Figure 5. Visualisation of the seven vertical cloud-aerosol structure classes. Classes $\mathrm{C} 1-\mathrm{C} 4$ contain transparent cirrus clouds and are used to characterise the CiPS cirrus cloud detection (probability of detection) together with the $\mathrm{CTH}_{\mathrm{CiPS}}$, IOT $\mathrm{CiPS}$ and IWP $\mathrm{CiPS}_{\mathrm{Petrievals}}$. Classes C5-C7 contain no cirrus clouds and are used to characterise the false alarm rate of the CiPS cirrus cloud detection.

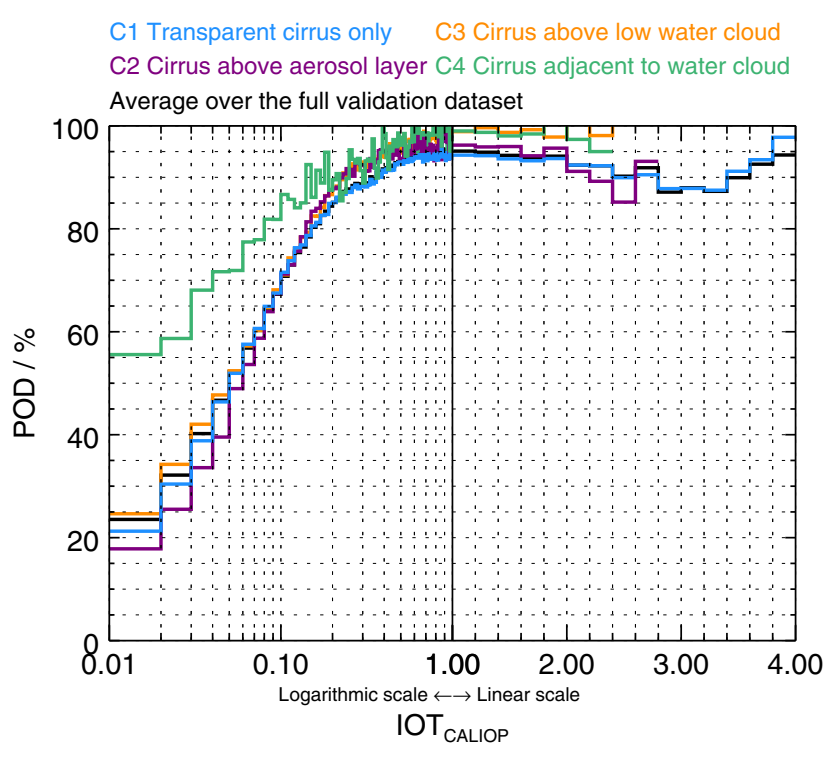

Figure 6. The cirrus POD of CiPS as a function of the IOT retrieved by CALIOP for the vertical cloud-aerosol structure classes $\mathrm{C} 1-\mathrm{C} 4$ along with the average POD over the full collocation dataset.

also indicated; class $\mathrm{C} 7$ with more the 1.7 million samples is the most common situation, while $\mathrm{C} 4$ with less than 14000 samples the most seldom.

Some CALIOP profiles do not fit into one of the seven classes, for example if the cirrus cloud is opaque or if the vertical distance between a cirrus cloud and an underlying liquid water cloud is between 0.5 and $4.0 \mathrm{~km}$. Furthermore, all CALIOP retrievals used for the validation of CiPS in Strandgren et al. (2017) do not necessarily pass the quality screening, since liquid water clouds and aerosols are included as well. In total, $75 \%$ of the CALIOP retrievals contained in the collocation dataset passed the quality screening and could be grouped into one of the seven classes. The remaining $25 \%$ were excluded from the present analysis. Please remember that the terms "transparent" and "opaque" in this context are solely related to the saturation of the CALIOP laser beam and indicate whether it was able to fully penetrate a cirrus cloud (transparent cirrus) or not (opaque cirrus).

\subsubsection{Cirrus cloud detection}

Figure 6 shows the POD of CiPS for the vertical cloudaerosol structure classes $\mathrm{C} 1-\mathrm{C} 4$, i.e. those classes defined in Sect. 4.4.1 that contain cirrus clouds. The POD is presented as a function of IOT $_{\text {CALIOP. }}$. For a better visualisation the scale is again logarithmic for IOT $_{\text {CALIOP }}<1.0$ and linear for IOT $_{\text {CALIOP }} \geq 1.0$. As a reference, the average POD for all cirrus clouds in the dataset, including those that did not fit any of the four classes $\mathrm{C} 1-\mathrm{C} 4$, is included.

The cirrus cloud detection by CiPS shows little interference with different vertical cloud-aerosol structures. It is, however, considerably easier for CiPS to detect a thin cirrus cloud when a liquid water cloud is present vertically close to the base altitude of the cirrus (C4). Even for subvisual cirrus the POD is close to $60 \%$ in such situations. If the vertical separation between the cirrus cloud and the liquid water cloud is larger ( $\geq 4.0 \mathrm{~km}, \mathrm{C} 3)$, only a marginal increase in POD with respect to profiles with no liquid water cloud below the cirrus is observed. For thicker cirrus clouds with IOT $_{\text {CALIOP }}>1.0$, the POD is close to $100 \%$ with a liquid water cloud below the cirrus (C3 and $\mathrm{C} 4)$, compared to $95 \%$ for scenes with only a transparent cirrus cloud (C1). An aerosol layer has a small effect on the CiPS cirrus detection in general, but for cirrus clouds with IOT $_{\text {CALIOP }}<0.08$ an aerosol layer appears to attenuate the radiative contrast of the cirrus, leading to a slightly lower POD. 


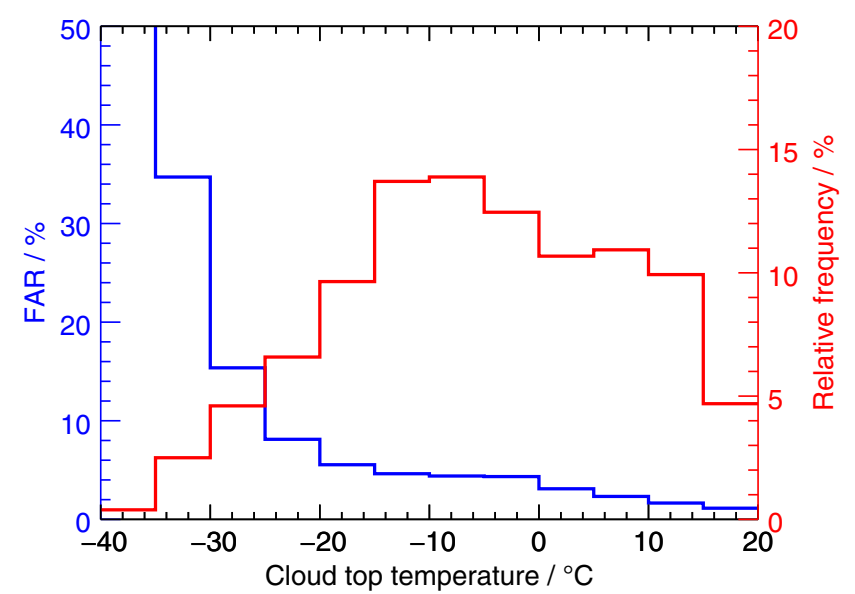

Figure 7. The FAR of CiPS for scenes with liquid water clouds (C5) as a function of the corresponding top temperature of the liquid water clouds. Along with the FAR, the relative frequency of occurrence of the different liquid water cloud top temperatures is shown.

For scenes with clear sky (C7) or thicker aerosol layers (C6) CiPS has a FAR of $3.2 \%$, meaning that it correctly classifies close to $97 \%$ of such scenes as cirrus-free (not further shown here). An increased average FAR of $5.5 \%$ is obtained when a liquid water cloud is present (C5). This is a result of CiPS falsely classifying some high liquid water clouds as cirrus clouds. Figure 7 shows the FAR for scenes with liquid water clouds (C5) as a function of the liquid water cloud top temperature along with the relative frequency of occurrence of the different cloud top temperatures. It is clear that the colder (higher up) the liquid water cloud is, the higher is the risk of falsely classifying it as a cirrus cloud. At temperatures below $-30^{\circ} \mathrm{C}$, the FAR is approx. $35-65 \%$. The relative frequency of such supercooled liquid water clouds is, however, low. Most liquid water clouds have a top temperature between -15 and $+15{ }^{\circ} \mathrm{C}$ and thus a clearly lower FAR of less than $5.0 \%$.

\subsubsection{Cirrus cloud properties}

Figure 8 shows the MAPE and MPE for the (a) $\mathrm{CTH}_{\mathrm{CiPS}}$, (b) $\mathrm{IOT}_{\mathrm{CiPS}}$ and (c) IWP $\mathrm{IWPS}_{\mathrm{CPS}}$ retrievals as functions of the corresponding reference retrievals by CALIOP and the vertical cloud-aerosol structure.

Within each $\mathrm{CTH}_{\mathrm{CALIOP}}$, IOT $\mathrm{IALIOP}_{\text {and }} \mathrm{IWP}_{\text {CALIOP }}$ interval in Fig. 8, the MAPE and MPE given by Eq. (3a) and (3b) are calculated. Again the results are presented with a logarithmic scale for IOT $_{\text {CALIOP }}<1.0$ and IWP CALIOP $<$ $10.0 \mathrm{~g} \mathrm{~m}^{-2}$ and with a linear scale for IOT $_{\text {CALIOP }} \geq 1.0$ and $\operatorname{IWP}_{\text {CALIOP }} \geq 10.0 \mathrm{~g} \mathrm{~m}^{-2}$. The average retrieval errors for all vertical cloud-aerosol structures are included as a reference and stem from Strandgren et al. (2017).

The presence of liquid water clouds ( $\mathrm{C} 3$ and $\mathrm{C} 4)$ has a negligible effect on the $\mathrm{CTH}_{\mathrm{CiPS}}$ retrieval. An aerosol layer be-
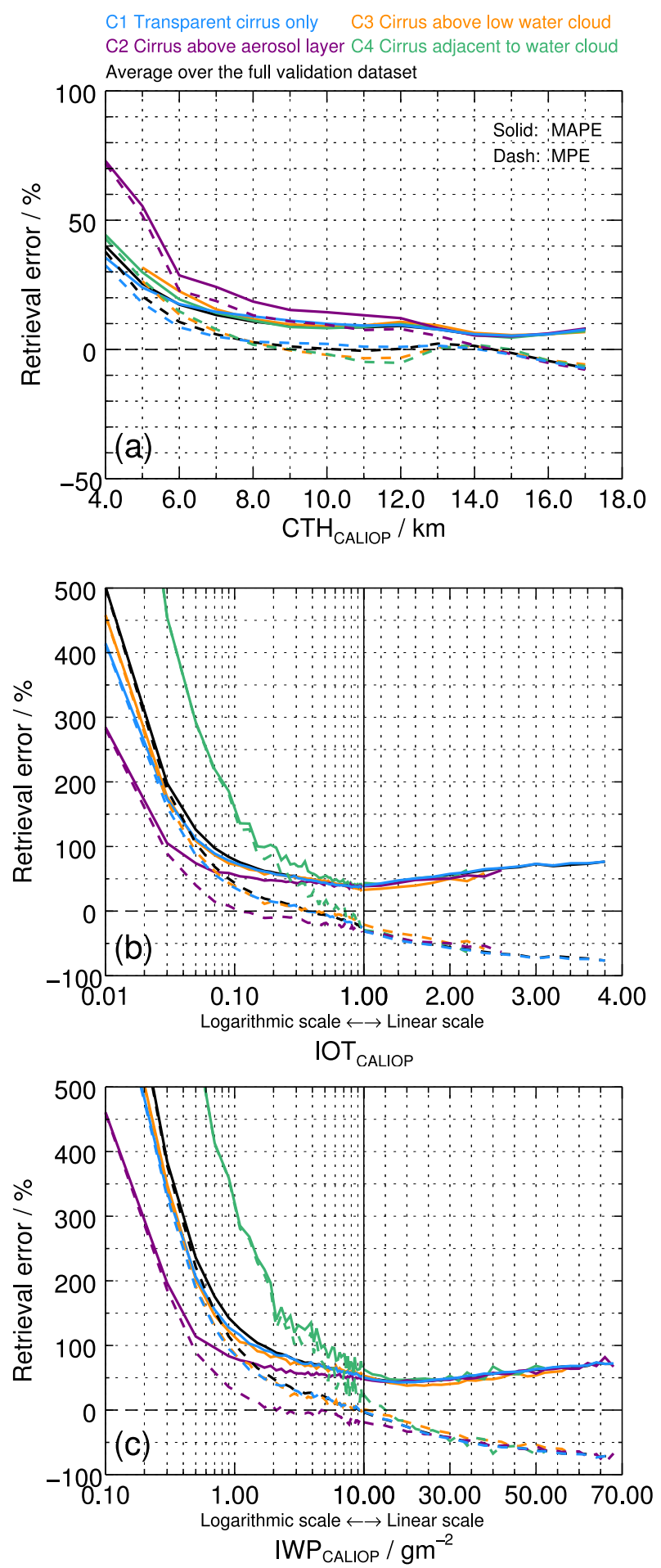

Figure 8. The MAPE (solid) and MPE (dash) of the $\mathrm{CTH}_{\mathrm{CiPS}}$ (a), $\mathrm{IOT}_{\mathrm{CiPS}}(\mathbf{b})$ and $\mathrm{IWP}_{\mathrm{CiPS}}(\mathbf{c})$ retrievals as functions of the corresponding reference retrievals from CALIOP. The retrieval errors of CiPS are presented for the four vertical cloud-aerosol structure classes C1-C4 (see Sect. 4.4.1), representing common cloud remote sensing situations, as well as the average retrieval errors for the full collocation dataset. 
low the cirrus cloud introduces a stronger positive bias (positive MPE), with a MAPE and MPE of up to $70 \%$ for the lowermost cirrus clouds. This is not necessarily an effect of the aerosol layer itself, and it is likely to be related to the fact that most aerosol layers with AOT $>0.2$ are found in the tropical regions (not shown here), where CTHs are typically higher leading to a stronger tendency of overestimating comparably low CTHs. This effect is seen to diminish with increasing $\mathrm{CTH}_{\text {CALIOP. }}$. At $\mathrm{CTH}_{\text {CALIOP }}=9.0 \mathrm{~km}$ the MAPE introduced by an underlying aerosol layer is approx. $5 \%$ larger compared to retrievals without an aerosol layer. Above $13 \mathrm{~km}$, the aerosol layer has no effect on the $\mathrm{CTH}_{\mathrm{CiPS}}$ retrieval error.

The presence of a low liquid water cloud below the cirrus $(\mathrm{C} 3)$ has a negligible effect on the IOT $_{\mathrm{CiPS}}$ and IWP $_{\mathrm{CiPS}}$ retrievals, with the same MPE and MAPE as for situations with solely clear sky or background aerosols below the cirrus cloud (C1). If the liquid water cloud is located vertically close or adjacent to the cirrus (C4), the retrieval error clearly increases for thin cirrus clouds. The increase in error for those retrievals is seen for IOT $_{\text {CALIOP }} \lesssim 0.5$ and IWP $_{\text {CALIOP }} \lesssim 10.0 \mathrm{~g} \mathrm{~m}^{-2}$ and increases rapidly with decreas-

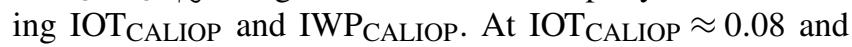
$\mathrm{IWP}_{\text {CALIOP }} \approx 2.0 \mathrm{~g} \mathrm{~m}^{-2}$, the MAPE is $200 \%$ for class $\mathrm{C} 4$, which is about twice the error of the $\mathrm{IOT}_{\mathrm{CiPS}} / \mathrm{IWP}_{\mathrm{CiPS}}$ retrievals for situations with solely clear sky or background aerosols below the cirrus cloud (C1). This pattern is to be expected as it is impossible for a radiometer to know where the transition between ice and liquid water occurs when the two clouds are not vertically well separated, especially since the liquid water cloud is thick and thus opaque to infrared radiation. Furthermore, it is more difficult to extract information about the cirrus from the brightness temperature differences, also utilising the regional maximum brightness temperatures, if the vertical separation, and hence the radiative contrast between the cirrus cloud and the underlying liquid water cloud, is small. A corresponding increase is observed for the MPE, meaning that the increased MAPE is a result of larger overestimations of IOT $_{\mathrm{CiPS}}$ and IWP $\mathrm{IPPS}_{\mathrm{CP}}$.

Opposite to the $\mathrm{CTH}_{\mathrm{CiPs}}$ retrieval, an aerosol layer below the cirrus cloud $(\mathrm{C} 2)$ reduces the IOT $\mathrm{CiPS}_{\mathrm{C}}$ and $\mathrm{IWP}_{\mathrm{CiPS}}$ retrieval errors for thin cirrus clouds. This does not imply that it is easier to retrieve the IOT $_{\mathrm{CiPS}}$ and IWP $_{\mathrm{CiPS}}$ of thin cirrus clouds when an aerosol layer is present below the cirrus. It is rather related to the fact that CiPS predominantly overes-

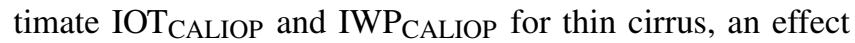
that is reduced if an aerosol layer is present below the cirrus.

\subsection{The CiPS retrieval errors as a function of optical thickness and cloud top height}

In this section we investigate the retrieval errors of CiPS as a function of IOT $_{\text {CALIOP }}$ and $\mathrm{CTH}_{\text {CALIOP. This gives infor- }}$ mation about typical errors of CiPS for different types of cirrus clouds (e.g. low and thick or high and thin cirrus). To remove any effects from different vertical cloud-aerosol structures, again only those profiles with transparent cirrus clouds and possible faint aerosols (AOT $\leq 0.2$ ) as defined by CALIOP L2 data are used (class $\mathrm{C} 1$ in Sect. 4.4.1). In other words, this shows typical CiPS retrieval errors for all transparent cirrus clouds occurring in the collocation dataset. This distribution is depicted in Fig. 9c, which represents a 2-D histogram with IOT $_{\text {CALIOP }}$ on the horizontal axis and $\mathrm{CTH}_{\text {CALIOP }}$ on the vertical axis. The colour map shows the number of occurrences for each combination of IOT CALIOP and $\mathrm{CTH}_{\mathrm{CALIOP}}$ in the collocation dataset. As mentioned in Sect. 2.3, both the collocation dataset and the training datasets used to train CiPS consist of a random subset of CALIOP data collected over a time period of almost 6 years and do to some extent (limited by the sun-synchronous orbit of CALIPSO) represent the natural distribution of IOT and $\mathrm{CTH}$ frequencies and their combinations. The occurrences in Fig. 9c are thus to a large extent representative for the corresponding occurrences in the dataset used to train CiPS as well. The highest occurrences of cirrus clouds in Fig. 9c are between 9 and $17 \mathrm{~km}$, with tropical cirrus covering the highaltitude cirrus fraction and mid- to low-latitude cirrus covering the low-altitude cirrus fraction. Low cirrus clouds are thicker than high cirrus, with an occurrence peak for cirrus with $\mathrm{CTH}_{\mathrm{CALIOP}}$ between 10.5 and $12.5 \mathrm{~km}$ and IOT $_{\mathrm{CALIOP}}$ between 0.3 and 1.0.

Figure 9a and $\mathrm{b}$ show two 2-D histograms with the IOT $_{\text {CALIOP }}$ and $\mathrm{CTH}_{\mathrm{CALIOP}}$ on the horizontal and vertical axes respectively. The colour maps show the MAPE and MPE of the $\mathrm{CTH}_{\mathrm{CiPS}}$ retrievals with respect to the reference CALIOP data (Eq. 3).

The $\mathrm{CTH}_{\mathrm{CiPS}}$ retrieval shows a stable performance with a MAPE between 5 and $15 \%$ for most combinations of top height and optical thickness. To accurately retrieve the CTH (and IOT/IWP) from the satellite, a clear radiative contrast between the cirrus cloud and the Earth's surface or low liquid water clouds is favourable. For optically thin cirrus clouds, radiation from below has a larger contribution to the observed brightness temperatures, which reduces the radiative contrast between the cirrus cloud and the underlying surface. Similarly, the radiative contrast decreases if the cirrus cloud is located further down in the atmosphere at warmer temperatures, with more water vapour above the cirrus cloud that makes the interpretation of window channel brightness temperatures and brightness temperature differences more difficult. These effects can be seen in the retrieval errors, with generally decreasing MAPE for increasing $\mathrm{CTH}_{\mathrm{CALIOP}}$ and

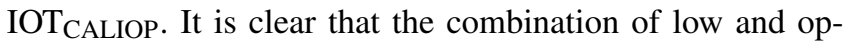
tically thin cirrus induce the maximum $\mathrm{CTH}_{\mathrm{CiPS}}$ retrieval errors (MAPE $\gtrsim 25 \%$ ) while high and optically thick cirrus induce the minimum $\mathrm{CTH}_{\mathrm{CiPS}}$ retrieval errors (MAPE $\approx$ $5 \%)$. The lowest retrieval errors are observed at high altitudes $\left(\mathrm{CTH}_{\mathrm{CALIOP}} \in[15,17] \mathrm{km}\right)$, where the $\mathrm{CTH}_{\mathrm{CiPS}}$ can be retrieved with a small error also for sub-visual cirrus. Similar features are observed using an optimal estimation method in Iwabuchi et al. (2016). For thin to sub-visual cirrus 

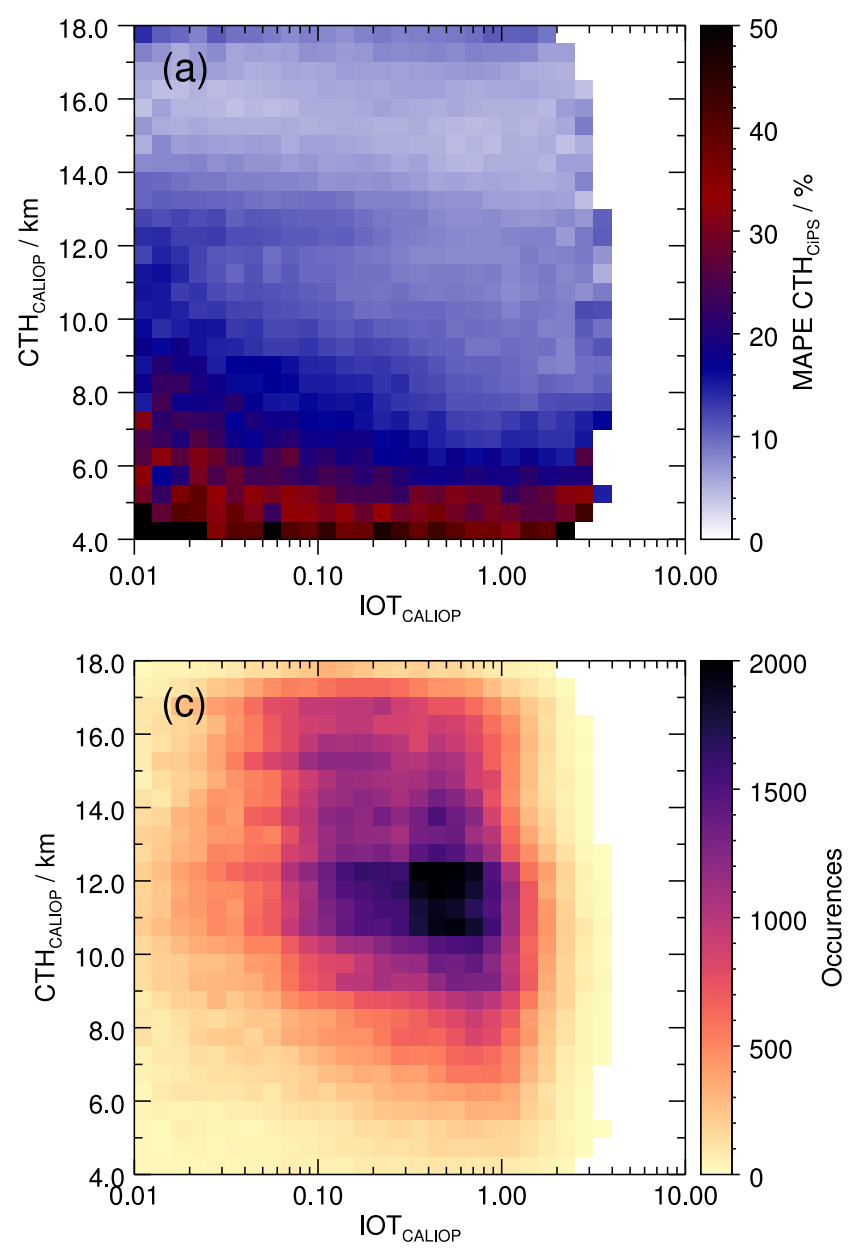
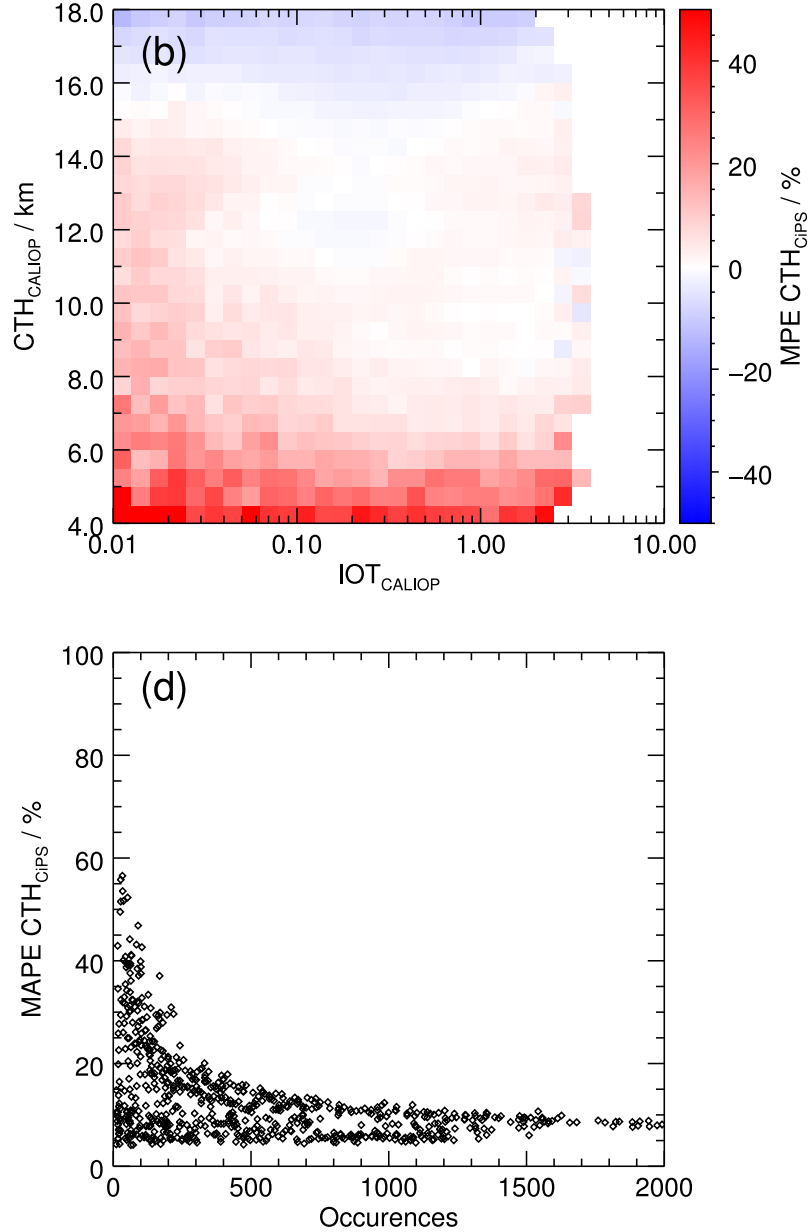

Figure 9. (a) Two-dimensional histogram showing the MAPE of the $\mathrm{CTH}_{\mathrm{CiPS}}$ retrievals as a function of the reference retrieval quantities IOT $_{\text {CALIOP }}$ and $\mathrm{CTH}_{\text {CALIOP. }}$ (b) Two-dimensional histogram showing the MPE of the $\mathrm{CTH}_{\mathrm{CiPS}}$ retrievals as a function of IOT $\mathrm{CALIOP}$ and $\mathrm{CTH}_{\text {CALIOP. (c) Two-dimensional histogram showing the number of occurrences for different combinations of IOT }}$ CALIOP $_{\text {and }} \mathrm{CTH}_{\mathrm{CALIOP}}$. (d) The MAPE of the $\mathrm{CTH}_{\mathrm{CiPS}}$ retrievals for the different $\mathrm{IOT}_{\mathrm{CALIOP}} / \mathrm{CTH}_{\mathrm{CALIOP}}$ combinations as a function of the number of occurrences (each diamond represents two corresponding grid boxes in $\mathbf{a}$ and $\mathbf{c}$ ).

clouds, CiPS is more likely to overestimate the CTH (positive MPE). With increasing IOT $_{\text {CALIOP }}$ the bias weakens, and for IOT $_{\text {CALIOP }}>0.05$ and $\mathrm{CTH}_{\text {CALIOP }}>8 \mathrm{~km}$ CiPS is mostly unbiased $(\mathrm{MPE} \approx 0)$. As already discussed in Strandgren et al. (2017), the extreme high and low $\mathrm{CTH}_{\mathrm{CALIOP}}$ are primarily under- and overestimated though, irrespective of IOT $_{\text {CALIOP. }}$

A correlation between higher MAPE and a low number of occurrences is evident. For the region of low optically thin cirrus, where the MAPE of the $\mathrm{CTH}_{\mathrm{CiPS}}$ retrieval is highest, there are only few points. This is further clarified in Fig. 9d, showing the MAPE of the $\mathrm{CTH}_{\mathrm{CiPS}}$ retrieval as a function of the number of occurrences. Each diamond in Fig. 9d represents one pair of grid boxes in Fig. 9a and c (708 pairs of boxes with valid data are represented). It is clear that the high MAPEs rarely occur and that most $\mathrm{CTH}_{\mathrm{CiPS}}$ retrievals have comparably low MAPEs. This gives us primarily three pieces of information. (1) The learning of the ANNs is sensitive to the distribution of the training dataset, leading to difficulties to accurately retrieve the cirrus properties for comparably rare situations. An effort was made to balance the training datasets for CiPS by adding duplicates for some rare situations (Sect. 3.4.2 in Strandgren et al., 2017) to increase their weight during the training. This approach does not, however, introduce any new information that the ANNs can learn from. Nevertheless, not even a perfectly balanced dataset is likely to result in an ANN that performs equally good for all kinds of cirrus clouds and retrieval conditions, as certain retrieval conditions have physical limitations, as discussed above for low and optically thin cirrus clouds. We also see that CiPS can retrieve the CTH for high sub-visual cirrus clouds with a low MAPE despite a low number occurrences. (2) With comparably few occurrences, the high MAPEs of CiPS have a small effect for the average usage of CiPS, as the MAPE for 

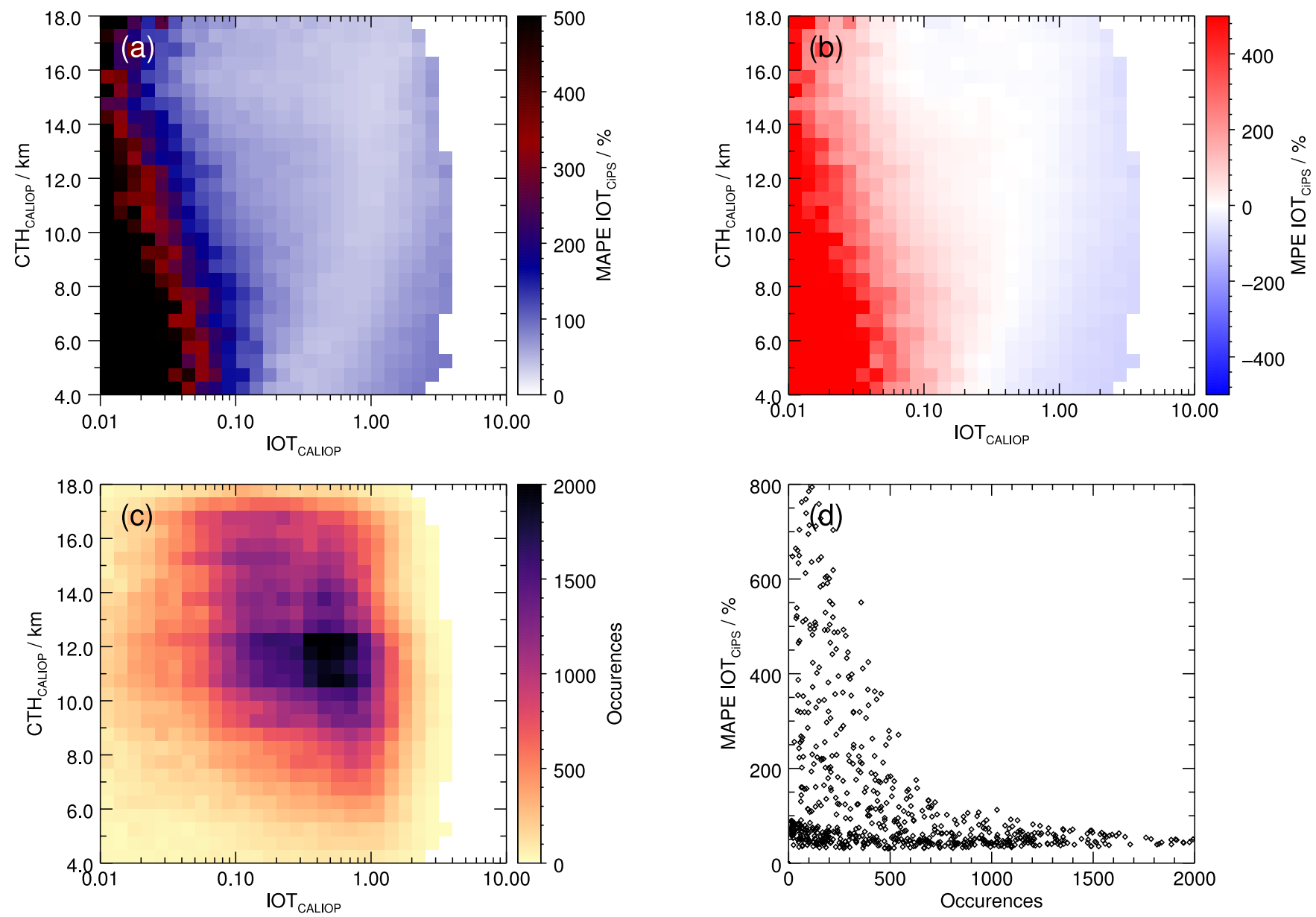

Figure 10. (a) Two-dimensional histogram showing the MAPE of the IOT $_{\mathrm{CiPS}}$ retrievals as a function of the reference retrieval quantities IOT $_{\text {CALIOP and }} \mathrm{CTH}_{\text {CALIOP. (b) Two-dimensional histogram showing the MPE of the } \text { IOT }_{\mathrm{CiPS}} \text { retrievals as a function of IOT }} \mathrm{CALIOP}_{\text {and }}$

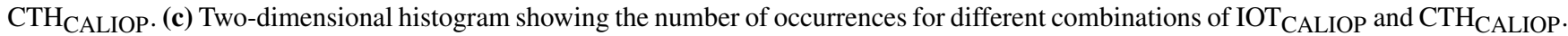
(d) The MAPE of the IOT $_{\mathrm{CiPS}}$ retrievals for the different $\mathrm{IOT}_{\mathrm{CALIOP}} / \mathrm{CTH}_{\mathrm{CALIOP}}$ combinations as a function of the number of occurrences (each diamond represents two corresponding grid boxes in $\mathbf{a}$ and $\mathbf{c}$ )

the comparably common situations is low. (3) Due to their few occurrences, the high MAPEs of CiPS have a low statistical value such that these values have to be treated with caution.

On average CiPS can retrieve the CTH with a MAPE around $8 \%$ and zero bias (MPE) for the most common combinations of $\mathrm{CTH}_{\mathrm{CALIOP}}$ and IOT $_{\text {CALIOP. Taking the number }}$ of occurrences into account, which represents the natural distribution of transparent cirrus clouds observed by CALIOP, $37 \%$ of all $\mathrm{CTH}_{\mathrm{CiPS}}$ retrievals have a MAPE of $5 \%$ or less. Another 27 and $16 \%$ of all retrievals have a MAPE between 5 and 10 and between 10 and $15 \%$ respectively.

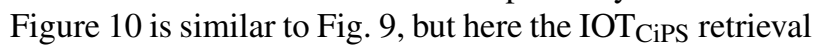
errors are in focus. Figure 10a-c again show 2-D histograms with IOT $_{\text {CALIOP }}$ on the horizontal axes and $\mathrm{CTH}_{\text {CALIOP }}$ on the vertical axes. The colour maps show (a) the MAPE and (b) the MPE of the IOT $_{\mathrm{CiPS}}$ retrievals with respect to the CALIOP reference retrievals and (c) the corresponding num- ber of occurrences for the different IOT $_{\text {CALIOP }} / \mathrm{CTH}_{\mathrm{CALIOP}}$ combinations. Figure $10 \mathrm{c}$ is consequently a duplicate of Fig. 9c but is included twice for the reader's convenience. Please note that the retrieval errors are significantly larger for IOT $_{\text {CiPs }}$ compared to $\mathrm{CTH}_{\mathrm{CiPS}}$ and the axes for the MAPE and MPE now range from 0 to $500 \%$ and from -500 to $500 \%$ respectively. The MAPE of the $\mathrm{IOT}_{\mathrm{CiPS}}$ retrievals as a function of the number of occurrences is shown in Fig. 10d. Similarly to the $\mathrm{CTH}_{\mathrm{CiPS}}$ retrievals, the $\mathrm{IOT}_{\mathrm{CiPS}}$ retrieval errors show clear patterns across the IOT $_{\text {CALIOP }}$ and $\mathrm{CTH}_{\text {CALIOP }}$ domains. The large retrieval errors for thin cirrus clouds already shown in Strandgren et al. (2017) are evident but are seen to decrease with increasing $\mathrm{CTH}_{\text {CALIOP. Above }}$ $14 \mathrm{~km}$ CiPS can estimate the IOT with a MAPE (Fig. 10a) of $30-120 \%$ down to sub-visual cirrus clouds. Again, the combination of low $\left(\mathrm{CTH}_{\mathrm{CALIOP}}<8 \mathrm{~km}\right)$ and optically thin $\left(\mathrm{IOT}_{\mathrm{CALIOP}}<0.1\right)$ cirrus induces the largest $\mathrm{IOT}_{\mathrm{CiPS}}$ retrieval errors (MAPE $>150 \%)$, while high $\left(\mathrm{CTH}_{\mathrm{CALIOP}}>\right.$ 
$13 \mathrm{~km}$ ) and optically thicker (IOT $\mathrm{CALIOP}>0.06$ ) cirrus induce the smallest retrieval errors (MAPE between 30 and $80 \%$ and MPE close to zero). Furthermore, there is a band

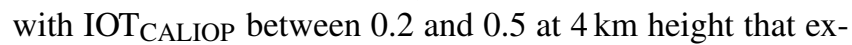
pands with $\mathrm{CTH}_{\mathrm{CALIOP}}$ to reach IOT $_{\mathrm{CALIOP}}$ between 0.1 and 1.0 at $16 \mathrm{~km}$ where the MAPE is smaller than $50 \%$. The smallest bias (MPE, Fig. 10b) is observed where the MAPE is lowest and increases slightly with decreasing $\mathrm{CTH}_{\mathrm{CALIOP}}$. For IOT $_{\text {CALIOP }}>0.3$, the IOT $_{\text {CiPS retrieval has a negative or }}$ zero bias on average (MPE between -80 and $0 \%$ ), whereas for IOT $_{\text {CALIOP }}<0.3$ the IOT $_{\text {CiPS retrieval has no or a posi- }}$ tive (up to $400 \%$ or more) bias.

Again an evident correlation between low MAPEs and a high number of occurrences is observed (Fig. 10d). Even though high MAPEs of $800 \%$ are possible, the large majority of the IOT $_{\mathrm{CiPS}}$ retrievals have MAPEs between 50 and $150 \%$. Please also note that a $800 \%$ MAPE observed at $\mathrm{IOT}_{\mathrm{CALIOP}}=0.01$ translates into a small absolute error (0.08). Similar optical thickness retrieval errors are shown for the optimal estimation retrieval by Iwabuchi et al. (2016), demonstrating that the large errors are not an artefact of the ANN but rather due to physical constraints discussed above. There are approx. 250 points/diamonds with less than 200 occurrences and low MAPE $(<100 \%)$. Those points represent cirrus clouds with a comparably high optical thickness (IOT CALIOP $_{2}$ 1.5). In this region CiPS predominantly under-

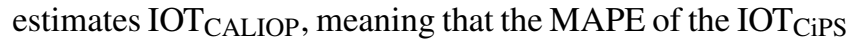
retrieval is bounded above by $100 \%$.

On average CiPS can retrieve the IOT with a MAPE around $50 \%$ and bias around $\pm 10 \%$ for the most common combinations of $\mathrm{CTH}_{\mathrm{CALIOP}}$ and IOT $_{\text {CALIOP. Taking }}$ the number of occurrences into account, again representing the natural distribution of transparent cirrus clouds observed by CALIOP, $55 \%$ of all IOT $_{\mathrm{CiPS}}$ retrievals have a MAPE of $50 \%$ or less. Another $28 \%$ of the retrievals have a MAPE between 50 and $100 \%$, meaning that only $17 \%$ of the retrievals have a MAPE larger than $100 \%$.

The corresponding results for the IWP $\mathrm{IPSS}_{\mathrm{CP}}$ retrieval are similar to those of the IOT $_{\mathrm{CiPS}}$ and are therefore not further presented here.

\subsection{Noise sensitivity analysis of CiPS}

In this section the effect of small noisy perturbations in the input data from SEVIRI propagating through the ANNs is quantified. The noise sensitivity analysis is performed for the $\mathrm{CTH}_{\mathrm{CiPS}}$, IOT $\mathrm{CiPS}$ and $\mathrm{IWP}_{\mathrm{CiPS}}$ retrievals. The collocation dataset described in Sect. 2.3 is used for this purpose in order to have a large temporal and spatial coverage. CiPS classifies 1.3 million points in the collocation dataset as icy, for which the $\mathrm{CTH}_{\mathrm{CiPS}}$, IOT $\mathrm{CiPS}$ and $\mathrm{IWP}_{\mathrm{CiPS}}$ is retrieved. Along with the standard CiPS retrieval using the observed SEVIRI brightness temperatures, another 100 retrievals for every point are performed where the SEVIRI brightness tem- peratures are randomly perturbed within the respective radiometric noise estimate ranges.

\subsubsection{Perturbing the SEVIRI brightness temperatures}

The estimated SEVIRI NE $\Delta T$ reported at reference temperatures as given in EUMETSAT (2007) (see the second column of Table 1) are smaller than $0.1 \mathrm{~K}$ for SEVIRI window and water vapour channels and smaller than $0.2 \mathrm{~K}$ for the $\mathrm{CO}_{2}$ channel. However, these reference temperatures are higher than for typical cirrus cloud retrievals. Therefore, the reported noise levels are scaled to the respective cirrus cloud brightness temperatures observed by SEVIRI. In a first step the NE $\Delta T$ are converted to NE $\Delta R$ (noise-equivalent radiance differences) using the derivative of Planck's law (with respect to temperature, $T$ ) at the reported reference temperatures and respective wavelengths (the centre channel wavelength in the first column of Table 1 is used for this purpose). In a second step the NE $\Delta R$ are converted back to NE $\Delta T$ at the brightness temperature of the corresponding cirrus cloud retrievals (P. Schöbel-Pattiselanno, EUMETSAT, personal communication, 2017). This results in an individual noise level estimate for all brightness temperatures observed by SEVIRI and used for the standard CiPS retrieval. So with 1.3 million cirrus cloud retrievals in the collocation dataset and 9 SEVIRI brightness temperatures as input (6 brightness temperatures and 3 regional maximum temperatures, Sect. 3.2), a total of $9 \times 1.3 \times 10^{6}$ individual radiometric noise level estimates are obtained. Please note that those are not metrologically traceable per-pixel noise estimates; instead all noise estimates are directly related via the observed brightness temperatures to the overall noise estimates of the single channels reported in the second column in Table 1.

When the radiometric noise in the respective channels is scaled to the observed brightness temperatures, colder cirrus cloud observations get higher radiometric noise levels compared to warmer observations. The third column in Table 1 shows the radiometric noise levels for the six SEVIRI channels used by CiPS at reference brightness temperatures given by typical cirrus cloud observations. Those reference temperatures constitute the average brightness temperatures observed by the respective channels across all CiPS cirrus clouds retrievals in the collocation dataset. It is clear that the noise level estimates of the cirrus cloud observations are higher compared to the noise levels at the warmer reference brightness temperatures reported by EUMETSAT (2007).

Each of the $9 \times 1.3 \times 10^{6}$ brightness temperature observations in the collocation dataset is associated with a Gaussian distribution with zero mean and standard deviation provided by the $9 \times 1.3 \times 10^{6}$ individual radiometric noise level estimates produced above. Each Gaussian distribution is finally sampled randomly 100 times yielding $9 \times 1.3 \times 10^{6} \times 100$ uncorrelated noise perturbations across the different SEVIRI input brightness temperatures. Hence, a set of 100 randomly perturbed retrievals is obtained for each cirrus cloud retrieval 
in the collocation dataset that can be directly compared to the corresponding standard (unperturbed) retrieval of CiPS.

\subsubsection{Noise sensitivity of CiPS}

The noise sensitivity of the $\mathrm{CTH}_{\mathrm{CiPS}}$, IOT $\mathrm{CiPS}$ and IWP $\mathrm{CiPS}_{\mathrm{P}}$ retrievals is determined by calculating the root-mean-square deviation (RMSD) between the standard retrievals and the corresponding 100 perturbed retrievals for the 1.3 million icy collocations. The RMSD is defined as

$\operatorname{RMSD}=\sqrt{\frac{1}{100} \sum_{i=1}^{100}\left(S-P_{i}\right)^{2}}$,

where $S$ is the standard CiPS retrieval and $P_{i}$ are the perturbed retrievals $(i=1, \ldots, 100)$. The sum spans over all 100 perturbed retrievals.

Figure 11 shows the RMSD for (a) $\mathrm{CTH}_{\mathrm{CiPS}}$, (b) $\mathrm{IOT}_{\mathrm{CiPS}}$ and (c) IWP CiPs $_{\text {as }}$ functions of the respective quantities. For $\mathrm{IOT}_{\mathrm{CiPS}}$ and IWP $\mathrm{CiPS}_{\mathrm{C}}$ only retrievals classified as transparent by $\mathrm{CiPS}\left(\mathrm{OPF}_{\mathrm{CiPS}}=0\right)$ are included. This reduces the number of samples from 1.3 to approx. 1 million. Please note that again the results are presented with a logarithmic scale for IOT $_{\text {CALIOP }}<1.0$ and IWP CALIOP $<10.0 \mathrm{~g} \mathrm{~m}^{-2}$ and with a linear scale for IOT $_{\text {CALIOP }} \geq 1.0$ and IWP ${ }_{\text {CALIOP }} \geq$ $10.0 \mathrm{~g} \mathrm{~m}^{-2}$. The surface type and the vertical cloud-aerosol structures are not taken into account for the noise sensitivity analysis and the reported results represent the average sensitivity to radiometric noise across all retrieval conditions.

The $\mathrm{CTH}_{\mathrm{CiPS}}$ retrieval is clearly robust with a low sensitivity to noise in the SEVIRI input data. The RMSD is around $100 \mathrm{~m}$ throughout the whole $\mathrm{CTH}_{\mathrm{CiPS}}$ range.

The IOT $_{\text {CiPS }}$ and IWP $_{\text {CiPS }}$ retrievals have similar noise sensitivities. The RMSD is less than $10 \%$ of the corresponding $\mathrm{IOT}_{\mathrm{CiPS}} / \mathrm{IWP}_{\mathrm{CiPS}}$ throughout most of the $\mathrm{IOT}_{\mathrm{CiPS}}$ and IWP $_{\text {CiPS }}$ ranges. Only for sub-visual cirrus the RMSD of CiPS is higher. For thicker cirrus, the IOT $\mathrm{IiPS}_{\mathrm{P}}$ and IWP $\mathrm{IiPS}_{\mathrm{C}}$ retrievals become more robust to SEVIRI noise as the respective curves flatten towards a constant sensitivity around 1.5 and $30 \mathrm{~g} \mathrm{~m}^{-2}$ for IOT $_{\mathrm{CiPS}}$ and IWP $\mathrm{IWPS}_{\mathrm{CPS}}$ respectively. For thin cirrus clouds, a small change in IOT/IWP induces a comparably large change in the cloud radiative properties. Similarly, a small change in the cloud radiative properties has a larger effect on the IOT and IWP for thin cirrus clouds compared to thicker cirrus where the IOT and IWP is higher. Consequently a small noisy perturbation applied to the SEVIRI input data has a larger impact on the IOT $_{\mathrm{CiPS}}$ and IWP $_{\mathrm{CiPS}}$ retrievals for thin cirrus clouds, leading to higher relative RMSD for thin cirrus and decreasing relative RMSD for thicker cirrus.

A noise sensitivity of 0.001 at a retrieved optical thickness of 0.01 is low and one may expect noise to have a stronger impact on the retrievals for such faint cirrus. The reported radiometric noise estimates of SEVIRI are, however, very low. Even for cold cirrus cloud retrievals, the radiometric noise
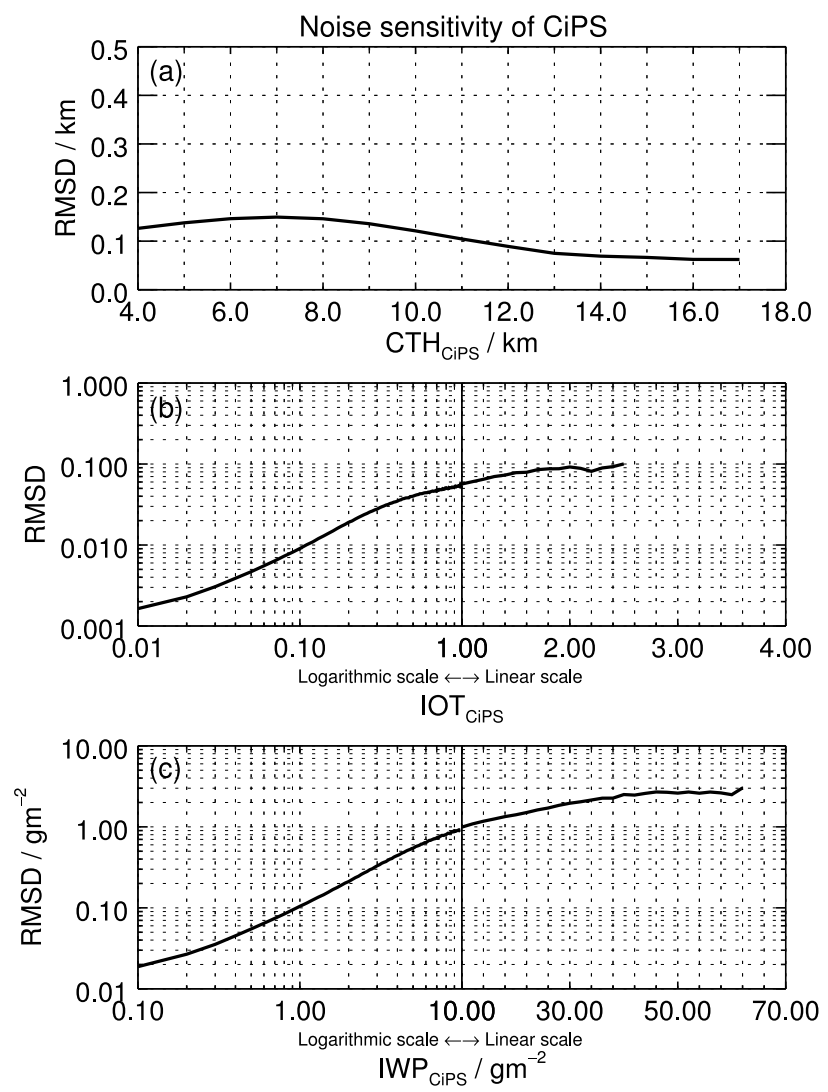

Figure 11. The noise sensitivity of the $\mathrm{CTH}_{\mathrm{CiPS}}(\mathbf{a}), \mathrm{IOT}_{\mathrm{CiPS}}(\mathbf{b})$ and IWP $_{\mathrm{CiPS}}$ (c) retrievals. The noise sensitivity is reported as the RMSD between the CiPS standard retrieval and 100 retrievals where the SEVIRI input data are randomly perturbed within the radiometric noise range of SEVIRI.

level is between 0.07 and $0.27 \mathrm{~K}$ on average for the six SEVIRI channels (see third column in Table 1), which corresponds to $0.3-1.1 \%$ of the observed average brightness temperatures. Furthermore, the noise is assumed to be Gaussian and peaks at zero across all perturbed retrievals and the individual SEVIRI input variables.

In Sect. 4.5 the retrieval error of CiPS is assessed to 515 and $50-150 \%$ for the $\mathrm{CTH}_{\mathrm{CiPS}}$ and $\mathrm{IOT}_{\mathrm{CiPS}} / \mathrm{IWP}_{\mathrm{CiPS}}$ retrievals respectively. In this section the radiometric noise of SEVIRI is shown to have a minor contribution to the retrieval error. Thus it is clear that the major part of the retrieval error stems from the clearly different characteristics and sensitivities of SEVIRI and CALIOP.

\section{Conclusions}

The CiPS algorithm (Strandgren et al., 2017) utilises a set of four artificial neural networks for the geostationary remote sensing of cirrus clouds with MSG/SEVIRI. In Strandgren et al. (2017) the retrieval accuracy was evaluated over all underlying surfaces types, vertical cloud-aerosol structures and 
IOT-CTH combinations combined. In this paper we perform a thorough characterisation of CiPS with respect to several aspects in order to (1) learn more about the CiPS retrieval accuracy under various retrieval conditions, (2) learn more about the ANN method for (cirrus) cloud remote sensing, and (3) learn more about potential and limitations of the synergistic use of the two, in many aspects very different, instruments, CALIOP and SEVIRI.

Over vegetated surfaces, CiPS retrieves the CTH, IOT and IWP with similar retrieval errors as over homogeneous water (ocean, lakes, rivers and wetlands). Over permanent snow and ice and barren (mostly desert), surface types that are known to induce difficult (cirrus) cloud remote sensing conditions (Frey et al., 2008; Holz et al., 2008), the IOT $_{\mathrm{CiPS}} / \mathrm{IWP}_{\mathrm{CiPS}}$ retrieval errors clearly increase only for thin cirrus clouds (IOT CALIOP $\lesssim 0.3$, IWP $_{\text {CALIOP }} \lesssim 5.0 \mathrm{~g} \mathrm{~m}^{-2}$ ) with respect to retrievals over water. Liquid water clouds below the observed cirrus have only a small or no effect on the $\mathrm{CTH}_{\mathrm{CiPS}}$ retrieval with respect to cirrus retrievals with no interfering cloud or aerosol layers below the cirrus. The IOT $_{\mathrm{CiPS}} / \mathrm{IWP}_{\mathrm{CiPS}}$ retrieval errors are clearly increased only if (1) the cirrus cloud is thin and (2) the liquid water cloud is vertically close or adjacent to the cirrus cloud. A liquid water cloud well separated $(>4.0 \mathrm{~km})$ from the cirrus cloud has no or small effect on the IOT $_{\mathrm{CiPS}} / \mathrm{IWP}_{\mathrm{CiPS}}$ retrieval errors, even for subvisual cirrus clouds. This shows that the limited vertical resolution of the thermal channels is sufficient to separate the contributions from these objects. This clearly differentiates CiPS from solar-channel-based Nakajima-King (Nakajima and King, 1990) retrievals (e.g. Platnick et al., 2003; Bugliaro et al., 2011; Stengel et al., 2014) that are only able to provide the optical thickness of the entire atmospheric column if no additional a priori information is used. The retrieval errors are further shown to decrease with increasing top height and optical thickness. For the most common combinations of $\mathrm{CTH}_{\mathrm{CALIOP}}$ and $\mathrm{IOT}_{\mathrm{CALIOP}}$, CiPS can retrieve the CTH with a MAPE around of $8 \%$ and no bias $(\mathrm{MPE}=0)$ and the IOT with a MAPE of around $50 \%$ and a bias of around $\pm 10 \%$ on average. Above $14 \mathrm{~km}$, IOT $\mathrm{CiPS}$ is retrieved with a MAPE between 30 and $120 \%$ down to sub-visual cirrus. Similar to physically based retrieval methods (e.g. Iwabuchi et al., 2016), CiPS struggles for low and optically thin cirrus clouds, where the radiative contrast between the cirrus clouds and the underlying surface is weaker. This implies that although CiPS (and ANNs in general) lacks the explicit implementation of physical principles, the CiPS cirrus cloud retrievals have similar limitations as physically based retrievals where the physical principles are explicitly implemented. We have shown that there are few conditions where CiPS can not retrieve meaningful results. And although significant retrieval errors are possible, we show that most of those conditions are rarely observed by SEVIRI, e.g. cirrus clouds over permanent snow and ice (see Fig. 2), transparent cirrus clouds (as seen by CiPS/CALIOP) vertically close or adjacent to liquid water clouds (see Fig. 5) and optically thin and low cirrus clouds (see Figs. 9c/10c).

The main limiting factors for the retrievals are shown to be physical constraints induced by for example low and optically thin cirrus clouds that have a weak radiative contrast to underlying liquid water clouds or land surfaces as seen from space. Only a small fraction of the retrieval errors $(\approx 10 \%)$ is estimated to stem from radiometric noise in the SEVIRI data. So even though the physical principles are not modelled explicitly in CiPS, the characterisation shows that the ANNs to a large extent could model the physical relationships between the input and output data. There are situations where limiting factors of the ANN method become apparent as well. For example CiPS underestimates the cirrus presence over desert due to the naturally low probability of cirrus cloud occurrence. Similarly, it overestimates the cirrus presence over tropical rainforests due to the naturally high probability of cirrus cloud occurrence. Likewise, CiPS is more likely to underestimate high $\mathrm{CTH}_{\text {CALIOP }}$ in regions where cirrus clouds are typically found at low altitudes. We also see that latitude has a considerably stronger relative importance than the brightness temperature at $13.4 \mu \mathrm{m}$ for $\mathrm{CTH}$, indicating that CiPS in that case modelled a statistical, rather than physical, relationship between input and output data. In general, auxiliary data like surface type flags and day of the year are shown to have a comparably small relative importance and for future developments within this field, surface emissivities as well as vertical humidity and temperature profiles would probably prove more useful. Using vertical profiles as input data would increase the computational costs though.

With this paper we have shown that the CiPS retrievals to a large extent show little interference with the underlying land surface type, the vertical cloud-aerosol structure below the cirrus and provide accurate results for common combinations of IOT and CTH. The idea of combining SEVIRI brightness temperature observations at a spatial resolution of $9 \mathrm{~km}^{2}$ or more with vertically resolved CALIOP lidar point measurements averaged over $5 \mathrm{~km}$ via a set of ANNs turns out to be very successful despite the different measurement principles and sensitivities. There are some conditions where increased retrieval errors are clearly observed, however. This proves the importance of such characterisations in order to more efficiently identify limitations and better understand the retrievals under different retrieval conditions. As we see that retrieval limitations to a large extent stem from physical constraints, this conclusion is not restricted to retrievals utilising ANNs. 


\section{Appendix A: List of abbreviations}

\begin{tabular}{ll}
\hline ANN & Artificial neural network \\
AOT & Aerosol optical thickness \\
BT & Brightness temperature \\
CCF & Cirrus cloud flag \\
CTH & Cloud top height \\
DOY & Day of year \\
FAR & False alarm rate \\
IOT & Ice optical thickness \\
ITCZ & Intertropical Convergence Zone \\
IWP & Ice water path \\
MAPE & Mean absolute percentage error \\
MLP & Multilayer perceptron \\
MPE & Mean percentage error \\
NE $\Delta T$ & Noise-equivalent temperature difference \\
NE $\Delta R$ & Noise-equivalent radiance difference \\
OPF & Opacity flag \\
POD & Probability of detection \\
RMSD & Root-mean-square deviation \\
TOA & Top of atmosphere \\
VZA & Viewing zenith angle \\
\hline
\end{tabular}


Data availability. CALIOP data products are available at CALIPSO Science Team (2015a, b, c, d). The MCD12C1 data product used to derive the land surface type classes is available at https://lpdaac.usgs.gov/data_access/data_pool. MSG/SEVIRI L1.5 data used as input for CiPS are available at https://www.eumetsat.int/website/home/Data/ DataDelivery/OnlineDataAccess/index.html. The surface skin temperature product from the ECMWF ERA Interim reanalysis dataset used as input for CiPS is available at http://apps.ecmwf.int/datasets/data/interim-full-daily/levtype=sfc/. CiPS data are available from the authors upon request.

Competing interests. The authors declare that they have no conflict of interest.

Acknowledgements. This research was supported by the DLR (Deutsches Zentrum für Luft- und Raumfahrt)/DAAD (Deutscher Akademischer Austauschdienst) Research Fellowship Programme für Doktoranden 14.

We thank the NASA Atmospheric Science Data Center for their kind support and for providing the V3 CALIOP layer data in a subsetted form. We are grateful to André Butz for his valuable input on the sensitivity analysis and general feedback on the manuscript. We also acknowledge the constructive comments of three anonymous referees and Florian Ewald that improved the quality of this paper. We gratefully acknowledge Pamela Schöbel-Pattiselanno and Debbie Richards for their guidance on how to interpret the reported radiometric noise of SEVIRI.

The SEVIRI data and the modelled surface temperature product used as input data for CiPS were provided by EUMETSAT (European Organisation for the Exploitation of Meteorological Satellites) and ECMWF (European Centre For Medium-Range Weather Forecasts) respectively. The MCD12C1 data product was retrieved from the online Data Pool, courtesy of the NASA Land Processes Distributed Active Archive Center (LP DAAC), USGS/Earth Resources Observation and Science (EROS) Center, Sioux Falls, South Dakota.

The article processing charges for this open-access publication were covered by a Research

Centre of the Helmholtz Association.

Edited by: Gianfranco Vulpiani

Reviewed by: three anonymous referees

\section{References}

Ackerman, S. A., Smith, W. L., Revercomb, H. E., and Spinhirne, J. D.: The 27-28 October 1986 FIRE IFO cirrus case study: spectral properties of cirrus clouds in the $8-12 \mu \mathrm{m}$ window, Mon. Weather Rev., 118, 2377-2388, https://doi.org/10.1175/15200493(1990)118<2377:TOFICC>2.0.CO;2, 1990.

Bugliaro, L., Zinner, T., Keil, C., Mayer, B., Hollmann, R., Reuter, M., and Thomas, W.: Validation of cloud property retrievals with simulated satellite radiances: a case study for SEVIRI, At- mos. Chem. Phys., 11, 5603-5624, https://doi.org/10.5194/acp11-5603-2011, 2011.

CALIPSO Science Team: CALIPSO/CALIOP Level 2, Lidar Cloud Layer Data, version 3.01, Hampton, VA, USA: NASA Atmospheric Science Data Center (ASDC), https://doi.org/10.5067/CALIOP/CALIPSO/CAL_LID_L2_ 05kmCLay-Prov-V3-01_L2-003.01, 2015a.

CALIPSO Science Team: CALIPSO/CALIOP Level 2, Lidar Cloud Layer Data, version 3.02, Hampton, VA, USA: NASA Atmospheric Science Data Center (ASDC), https://doi.org/10.5067/CALIOP/CALIPSO/CAL_LID_L2_ 05kmCLay-Prov-V3-02_L2-003.02, 2015b.

CALIPSO Science Team: CALIPSO/CALIOP Level 2, Lidar Aerosol Layer Data, version 3.01, Hampton, VA, USA: NASA Atmospheric Science Data Center (ASDC), https://doi.org/10.5067/CALIOP/CALIPSO/CAL_LID_L2_ 05kmALay-Prov-V3-01_L2-003.01, 2015c.

CALIPSO Science Team: CALIPSO/CALIOP Level 2, Lidar Aerosol Layer Data, version 3.02, Hampton, VA, USA: NASA Atmospheric Science Data Center (ASDC), https://doi.org/10.5067/CALIOP/CALIPSO/CAL_LID_L2_ 05kmALay-Prov-V3-02_L2-003.02, 2015d.

Ceccaldi, M., Delanoë, J., Hogan, R. J., Pounder, N. L., Protat, A., and Pelon, J.: From CloudSat-CALIPSO to EarthCare: evolution of the DARDAR cloud classification and its comparison to airborne radar-lidar observations, J. Geophys. Res.-Atmos., 118, 7962-7981, https://doi.org/10.1002/jgrd.50579, 2013.

Cesana, G., Chepfer, H., Winker, D., Getzewich, B., Cai, X., Jourdan, O., Mioche, G., Okamoto, H., Hagihara, Y., Noel, V., and Reverdy, M.: Using in situ airborne measurements to evaluate three cloud phase products derived from CALIPSO, J. Geophys. Res., 121, 5788-5808, https://doi.org/10.1002/2015JD024334, 2015JD024334, 2016.

Delanoë, J. and Hogan, R. J.: A variational scheme for retrieving ice cloud properties from combined radar, lidar, and infrared radiometer, J. Geophys. Res.-Atmos., 113, D07204, https://doi.org/10.1029/2007JD009000, 2008.

Delanoë, J. and Hogan, R. J.: Combined CloudSatCALIPSO-MODIS retrievals of the properties of ice clouds, J. Geophys. Res.-Atmos., 115, D00H29, https://doi.org/10.1029/2009JD012346, 2010.

Deng, M., Mace, G. G., Wang, Z., and Okamoto, H.: Tropical composition, cloud and climate coupling experiment validation for cirrus cloud profiling retrieval using CloudSat radar and CALIPSO lidar, J. Geophys. Res.-Atmos., 115, D00J15, https://doi.org/10.1029/2009JD013104, 2010.

De Paepe, B. and Dewitte, S.: Dust aerosol optical depth retrieval over a desert surface using the SEVIRI window channels, J. Atmos. Ocean. Tech., 26, 704-718, 2009.

DeSlover, D., Smith, W., Piironen, P., and Eloranta, E.: A methodology of measuring cirrus cloud visible-to-infrared spectral optical depth ratios, J. Atmos. Ocean. Tech., 16, 251-262, 1999.

Devasthale, A., Tjernström, M., Karlsson, K.-G., Thomas, M. A., Jones, C., Sedlar, J., and Omar, A. H.: The vertical distribution of thin features over the Arctic analysed from CALIPSO observations, Tellus B, 63, 77-85, https://doi.org/10.1111/j.16000889.2010.00516.x, 2011.

Donovan, D. and van Lammeren, A.: Cloud effective particle size and water content profile retrievals using combined lidar and 
radar observations. 1. Theory and examples, J. Geophys. Res.Atmos., 106, 27425-27448, 2001.

Eliasson, S., Buehler, S. A., Milz, M., Eriksson, P., and John, V. O.: Assessing observed and modelled spatial distributions of ice water path using satellite data, Atmos. Chem. Phys., 11, 375391, https://doi.org/10.5194/acp-11-375-2011, 2011.

EUMETSAT: Typical Radiometric Accuracy and Noise for MSG-1/2, available at: http://www.eumetsat.int/website/wcm/ idc/idcplg?IdcService $=$ GET_FILE\&dDocName $=$ PDF_TYP_ RADIOMET_ACC_MSG-1-2\&RevisionSelectionMethod= LatestReleased\&Rendition=Web (last access: 19 October 2017), EUM/OPS/TEN/07/0314, 2007.

Ewald, F., Bugliaro, L., Mannstein, H., and Mayer, B.: An improved cirrus detection algorithm MeCiDA2 for SEVIRI and its evaluation with MODIS, Atmos. Meas. Tech., 6, 309-322, https://doi.org/10.5194/amt-6-309-2013, 2013.

Frey, R. A., Ackerman, S. A., Liu, Y., Strabala, K. I., Zhang, H., Key, J. R., and Wang, X.: Cloud detection with MODIS. Part I: improvements in the MODIS cloud mask for collection 5, J. Atmos. Ocean. Tech., 25, 1057-1072, https://doi.org/10.1175/2008JTECHA1052.1, 2008.

Friedl, M. A., Sulla-Menashe, D., Tan, B., Schneider, A., Ramankutty, N., Sibley, A., and Huang, X.: MODIS collection 5 global land cover: algorithm refinements and characterization of new datasets, Remote Sens. Environ., 114, 168-182, https://doi.org/10.1016/j.rse.2009.08.016, 2010.

Gao, B.-C., Han, W., Tsay, S. C., and Larsen, N. F.: Cloud detection over the Arctic region using airborne imaging spectrometer data during the daytime, J. Appl. Meteorol., 37, 1421-1429, https://doi.org/10.1175/15200450(1998)037<1421:CDOTAR>2.0.CO;2, 1998.

Garnier, A., Pelon, J., Dubuisson, P., Faivre, M., Chomette, O., Pascal, N., and Kratz, D. P.: Retrieval of cloud properties using CALIPSO Imaging Infrared Radiometer. Part I: Effective emissivity and optical depth, J. Appl. Meteorol. Clim., 51, 14071425, 2012.

Garnier, A., Pelon, J., Dubuisson, P., Yang, P., Faivre, M., Chomette, O., Pascal, N., Lucker, P., and Murray, T.: Retrieval of cloud properties using CALIPSO imaging infrared radiometer. Part II: effective diameter and ice water path, J. Appl. Meteorol. Clim., 52, 2582-2599, 2013.

Garnier, A., Pelon, J., Vaughan, M. A., Winker, D. M., Trepte, C. R., and Dubuisson, P.: Lidar multiple scattering factors inferred from CALIPSO lidar and IIR retrievals of semi-transparent cirrus cloud optical depths over oceans, Atmos. Meas. Tech., 8, 27592774, https://doi.org/10.5194/amt-8-2759-2015, 2015.

Groß, S., Freudenthaler, V., Schepanski, K., Toledano, C., Schäfler, A., Ansmann, A., and Weinzierl, B.: Optical properties of long-range transported Saharan dust over Barbados as measured by dual-wavelength depolarization Raman lidar measurements, Atmos. Chem. Phys., 15, 11067-11080, https://doi.org/10.5194/acp-15-11067-2015, 2015.

Hastings, D. A. and Emery, W. J.: The advanced very high resolution radiometer (AVHRR)-A brief reference guide, Photogramm. Eng. Rem. S., 58, 1183-1188, 1992.

Heidinger, A. K., Li, Y., Baum, B. A., Holz, R. E., Platnick, S., and Yang, P.: Retrieval of cirrus cloud optical depth under day and night conditions from MODIS Collection 6 cloud property data, Remote Sens., 7, 7257-7271, 2015.
Heymsfield, A. J., Winker, D., and van Zadelhoff, G.J.: Extinction-ice water content-effective radius algorithms for CALIPSO, Geophys. Res. Lett., 32, L10807, https://doi.org/10.1029/2005GL022742, 2005.

Holl, G., Eliasson, S., Mendrok, J., and Buehler, S. A.: SPARE-ICE: synergistic ice water path from passive operational sensors, J. Geophys. Res.-Atmos., 119, 1504-1523, https://doi.org/10.1002/2013JD020759, 2014.

Holz, R., Ackerman, S., Nagle, F., Frey, R., Dutcher, S., Kuehn, R., Vaughan, M., and Baum, B.: Global Moderate Resolution Imaging Spectroradiometer (MODIS) cloud detection and height evaluation using CALIOP, J. Geophys. Res.-Atmos., 113, D00A19, https://doi.org/10.1029/2008JD009837, 2008.

Hulley, G. C., Hook, S. J., Abbott, E., Malakar, N., Islam, T., and Abrams, M.: The ASTER Global Emissivity Dataset (ASTER GED): mapping Earth's emissivity at 100 meter spatial scale, Geophys. Res. Lett., 42, 7966-7976, https://doi.org/10.1002/2015GL065564, 2015GL065564, 2015.

Inoue, T.: On the temperature and effective emissivity determination of semi-transparent cirrus clouds by bi-spectral measurements in the $10 \mu \mathrm{m}$ window region, J. Meteorol. Soc. Jpn., 63, 88-99, 1985.

Iwabuchi, H., Saito, M., Tokoro, Y., Putri, N. S., and Sekiguchi, M.: Retrieval of radiative and microphysical properties of clouds from multispectral infrared measurements, Prog. in Earth and Planet. Sci., 3, 32, https://doi.org/10.1186/s40645-016-0108-3, 2016.

King, M. D., Kaufman, Y. J., Menzel, W. P., and Tanré, D.: Remote sensing of cloud, aerosol, and water vapor properties from the Moderate Resolution Imaging Spectrometer (MODIS), IEEE T. Geosci. Remote, 30, 2-27, 1992.

Kox, S., Bugliaro, L., and Ostler, A.: Retrieval of cirrus cloud optical thickness and top altitude from geostationary remote sensing, Atmos. Meas. Tech., 7, 3233-3246, https://doi.org/10.5194/amt7-3233-2014, 2014.

Krebs, W., Mannstein, H., Bugliaro, L., and Mayer, B.: Technical note: A new day- and night-time Meteosat Second Generation Cirrus Detection Algorithm MeCiDA, Atmos. Chem. Phys., 7, 6145-6159, https://doi.org/10.5194/acp-7-6145-2007, 2007.

LeCun, Y., Denker, J. S., and Solla, S. A.: Optimal brain damage, in: Advances in Neural Information Processing Systems 2, edited by: Touretzky, D. S., 598-605, Morgan-Kaufmann, San Francisco, CA, USA, 1990.

Loveland, T. R. and Belward, A. S.: The IGBP-DIS global $1 \mathrm{~km}$ land cover data set, DISCover: first results, Int. J. Remote Sens., 18, 3289-3295, https://doi.org/10.1080/014311697217099, 1997.

Meerkötter, R., Schumann, U., Doelling, D., Minnis, P., Nakajima, T., and Tsushima, Y.: Radiative forcing by contrails, Ann. Geophys., 17, 1080-1094, 1999.

Menzel, W., Smith, W., and Stewart, T.: Improved cloud motion wind vector and altitude assignment using VAS, J. Appl. Meteorol., 22, 377-384, 1983.

Menzel, W. P., Frey, R. A., Zhang, H., Wylie, D. P., Moeller, C. C., Holz, R. E., Maddux, B., Baum, B. A., Strabala, K. I., and Gumley, L. E.: MODIS global cloudtop pressure and amount estimation: algorithm description and results, J. Appl. Meteorol. Clim., 47, 1175-1198, https://doi.org/10.1175/2007JAMC1705.1, 2008. 
Minnis, P., Sun-Mack, S., Young, D. F., Heck, P. W., Garber, D. P., Chen, Y., Spangenberg, D. A., Arduini, R. F., Trepte, Q. Z., Smith, W. L., Ayers, J. K., Gibson, S. C., Miller, W. F., Hong, G., Chakrapani, V., Takano, Y., Liou, K. N., Xie, Y., and Yang, P.: CERES Edition-2 cloud property retrievals using TRMM VIRS and Terra and Aqua MODIS data - Part I: algorithms, IEEE T. Geosci. Remote, 49, 4374-4400, https://doi.org/10.1109/TGRS.2011.2144601, 2011.

Minnis, P., Hong, G., Sun-Mack, S., Smith, W. L., Chen, Y., and Miller, S. D.: Estimating nocturnal opaque ice cloud optical depth from MODIS multispectral infrared radiances using a neural network method, J. Geophys. Res.-Atmos., 121, 4907-4932, https://doi.org/10.1002/2015JD024456, 2016.

Mioche, G., Jourdan, O., Ceccaldi, M., and Delanoë, J.: Variability of mixed-phase clouds in the Arctic with a focus on the Svalbard region: a study based on spaceborne active remote sensing, Atmos. Chem. Phys., 15, 2445-2461, https://doi.org/10.5194/acp15-2445-2015, 2015.

Nakajima, T. and King, M. D.: Determination of the optical thickness and effective particle radius of clouds from reflected solar radiation measurements. Part I: theory, J. Atmos. Sci., 47, 1878-1893, https://doi.org/10.1175/15200469(1990)047<1878:DOTOTA>2.0.CO;2, 1990.

Platnick, S., King, M. D., Ackerman, S. A., Menzel, W. P., Baum, B. A., Riedi, J. C., and Frey, R. A.: The MODIS cloud products: algorithms and examples from Terra, IEEE T. Geosci. Remote, 41, 459-473, https://doi.org/10.1109/TGRS.2002.808301, 2003.

Rosário, N. E., Yamasoe, M. A., Brindley, H., Eck, T. F., and Schafer, J.: Downwelling solar irradiance in the biomass burning region of the southern Amazon: dependence on aerosol intensive optical properties and role of water vapor, J. Geophys. Res.Atmos., 116, D18304, https://doi.org/10.1029/2011JD015956, 2011.

Rumelhart, D. E., Hinton, G. E., and Williams, R. J.: Learning internal representations by error propagation, in: Parallel Distributed Processing: Explorations in the Microstructure of Cognition, vol. 1, 318-362, MIT Press, Cambridge, MA, USA, 1986.

Schmetz, J., Holmlund, K., Hoffman, J., Strauss, B., Mason, B., Gaertner, V., Koch, A., and van de Berg, L.: Operational cloud-motion winds from Meteosat infrared images, J. Appl. Meteorol., 32, 1206-1225, https://doi.org/10.1175/15200450(1993)032<1206:OCMWFM>2.0.CO;2, 1993.

Schmetz, J., Pili, P., Tjemkes, S., Just, D., Kerkmann, J., Rota, S., and Ratier, A.: An introduction to Meteosat Second Generation (MSG), B. Am. Meteorol. Soc., 83, 977-992, https://doi.org/10.1175/15200477(2002)083<0977:AITMSG>2.3.CO;2, 2002.

Schmit, T. J., Goodman, S. J., Gunshor, M. M., Sieglaff, J., Heidinger, A. K., Bachmeier, A. S., Lindstrom, S. S., Terborg, A., Feltz, J., Bah, K., Rudlosky, S., Lindsey, D. T., Rabin, R. M., and Schmidt, C. C.: Rapid refresh information of significant events: preparing users for the next generation of geostationary operational satellites, B. Am. Meteorol. Soc., 96, 561-576, 2015.

Shettle, E.: Models of aerosols, clouds and precipitation for atmospheric propagation studies, in: Atmospheric propagation in the UV, visible, IR and mm-region and related system aspects, AGARD Conf. Proc. no. 454, 15-1-15-13, Copenhagen, Denmark, 9-13 October 1989.
Shupe, M. D., Matrosov, S. Y., and Uttal, T.: Arctic mixed-phase cloud properties derived from surfacebased sensors at SHEBA, J. Atmos. Sci., 63, 697-711, https://doi.org/10.1175/JAS3659.1, 2006.

Stengel, M., Kniffka, A., Meirink, J. F., Lockhoff, M., Tan, J., and Hollmann, R.: CLAAS: the CM SAF cloud property data set using SEVIRI, Atmos. Chem. Phys., 14, 4297-4311, https://doi.org/10.5194/acp-14-4297-2014, 2014.

Stephens, G. L., Vane, D. G., Boain, R. J., Mace, G. G., Sassen, K., Wang, Z., Illingworth, A. J., O'Connor, E. J., Rossow, W. B., Durden, S. L., Miller, S. D., Austin, R. T., Benedetti, A., Mitrescu, C., and Team, T. C. S.: The CloudSat mission and the A-train, B. Am. Meteorol. Soc., 83, 1771-1790, https://doi.org/10.1175/BAMS-83-12-1771, 2002.

Stevens, B. and Bony, S.: What are climate models missing?, Science, 340, 1053-1054, https://doi.org/10.1126/science.1237554, 2013.

Strandgren, J., Bugliaro, L., Sehnke, F., and Schröder, L.: Cirrus cloud retrieval with MSG/SEVIRI using artificial neural networks, Atmos. Meas. Tech., 10, 3547-3573, https://doi.org/10.5194/amt-10-3547-2017, 2017.

Stubenrauch, C. J., Rossow, W. B., Kinne, S., Ackerman, S., Cesana, G., Chepfer, H., Girolamo, L. D., Getzewich, B., Guignard, A., Heidinger, A., Maddux, B. C., Menzel, W. P., Minnis, P., Pearl, C., Platnick, S., Poulsen, C., Riedi, J., SunMack, S., Walther, A., Winker, D., Zeng, S., and Zhao, G.: Assessment of global cloud datasets from satellites: project and database initiated by the GEWEX radiation panel, B. Am. Meteorol. Soc., 94, 1031-1049, https://doi.org/10.1175/BAMS-D-12$00117.1,2013$.

Ten Hoeve, J. E., Jacobson, M. Z., and Remer, L. A.: Comparing results from a physical model with satellite and in situ observations to determine whether biomass burning aerosols over the Amazon brighten or burn off clouds, J. Geophys. Res.-Atmos., 117, D08203, https://doi.org/10.1029/2011JD016856, 2012.

Toth, T. D., Zhang, J., Campbell, J. R., Reid, J. S., Shi, Y., Johnson, R. S., Smirnov, A., Vaughan, M. A., and Winker, D. M.: Investigating enhanced Aqua MODIS aerosol optical depth retrievals over the mid-to-high latitude Southern Oceans through intercomparison with co-located CALIOP, MAN, and AERONET data sets, J. Geophys. Res.-Atmos., 118, 4700-4714, https://doi.org/10.1002/jgrd.50311, 2013.

Trigo, I. F., Peres, L. F., DaCamara, C. C., and Freitas, S. C.: Thermal land surface emissivity retrieved from SEVIRI/Meteosat, IEEE T. Geosci. Remote, 46, 307-315, https://doi.org/10.1109/TGRS.2007.905197, 2008.

Verlinde, J., Harrington, J. Y., Yannuzzi, V. T., Avramov, A., Greenberg, S., Richardson, S. J., Bahrmann, C. P., McFarquhar, G. M., Zhang, G., Johnson, N., Poellot, M. R., Mather, J. H., Turner, D. D., Eloranta, E. W., Tobin, D. C., Holz, R., Zak, B. D., Ivey, M. D., Prenni, A. J., DeMott, P. J., Daniel, J. S., Kok, G. L., Sassen, K., Spangenberg, D., Minnis, P., Tooman, T. P., Shupe, M., Heymsfield, A. J., and Schofield, R.: The mixed-phase Arctic cloud experiment, B. Am. Meteorol. Soc., 88, 205-221, https://doi.org/10.1175/BAMS-88-2-205, 2007.

Waliser, D. E., Li, J.-L. F., Woods, C. P., Austin, R. T., Bacmeister, J., Chern, J., Del Genio, A., Jiang, J. H., Kuang, Z., Meng, H., Minnis, P., Platnick, S., Rossow, W. B., Stephens, G. L., Sun- 
Mack, S., Tao, W.-K., Tompkins, A. M., Vane, D. G., Walker, C., and $\mathrm{Wu}, \mathrm{D} .:$ Cloud ice: a climate model challenge with signs and expectations of progress, J. Geophys. Res.-Atmos., 114, D00A21, https://doi.org/10.1029/2008JD010015, 2009.

Wang, C., Platnick, S., Zhang, Z., Meyer, K., and Yang, P.: Retrieval of ice cloud properties using an optimal estimation algorithm and MODIS infrared observations: 1. Forward model, error analysis, and information content, J. Geophys. Res.-Atmos., 121, 58095826, https://doi.org/10.1002/2015JD024526, 2015JD024526, 2016.

Weinzierl, B., Sauer, D., Esselborn, M., Petzold, A., Veira, A., Rose, M., Mund, S., Wirth, M., Ansmann, A., Tesche, M., Gross, S., and Freudenthaler, V.: Microphysical and optical properties of dust and tropical biomass burning aerosol layers in the Cape Verde region - an overview of the airborne in situ and lidar measurements during SAMUM-2, Tellus B, 63, 589-618, https://doi.org/10.1111/j.1600-0889.2011.00566.x, 2011.
Wetzel, C. and Brümmer, B.: An Arctic inversion climatology based on the European Centre Reanalysis ERA-40, Meteorol. Z., 20, 589-600, https://doi.org/10.1127/0941-2948/2011/0295, 2011.

Wilson, L. D., Curry, J. A., and Ackerman, T. P.: Satellite retrieval of lower-tropospheric ice crystal clouds in the polar regions, J. Climate, 6, 1467-1472, https://doi.org/10.1175/15200442(1993)006<1467:SROLTI>2.0.CO;2, 1993.

Winker, D. M., Pelon, J. R., and McCormick, M. P.: The CALIPSO mission: spaceborne lidar for observation of aerosols and clouds, in: Proc. SPIE, vol. 4893, Proc. SPIE 4893, Lidar Remote Sensing for Industry and Environment Monitoring III (21 March 2003), https://doi.org/10.1117/12.466539, 2003.

Winker, D. M., Vaughan, M. A., Omar, A., Hu, Y., Powell, K. A., Liu, Z., Hunt, W. H., and Young, S. A.: Overview of the CALIPSO Mission and CALIOP Data Processing Algorithms, J. Atmos. Ocean. Tech., 26, 2310-2323, https://doi.org/10.1175/2009JTECHA1281.1, 2009. 